\title{
Article \\ Strength, Fracture and Durability Characteristics of Ambient Cured Alkali-Activated Mortars Incorporating High Calcium Industrial Wastes and Powdered Reagents
}

\author{
Dhruv Sood (D) and Khandaker M. A. Hossain *(D) \\ Department of Civil Engineering, Ryerson University, Toronto, ON M5B 2K3, Canada; dhruv.sood@ryerson.ca \\ * Correspondence: ahossain@ryerson.ca
}

check for

updates

Citation: Sood, D.; Hossain, K.M.A. Strength, Fracture and Durability Characteristics of Ambient Cured Alkali-Activated Mortars Incorporating High Calcium Industrial Wastes and Powdered Reagents. Crystals 2021, 11, 1167. https://doi.org/10.3390/cryst11101167

Academic Editors: Shima Pilehvar and Luis G. Baltazar

Received: 30 August 2021

Accepted: 22 September 2021

Published: 25 September 2021

Publisher's Note: MDPI stays neutral with regard to jurisdictional claims in published maps and institutional affiliations.

Copyright: (c) 2021 by the authors. Licensee MDPI, Basel, Switzerland. This article is an open access article distributed under the terms and conditions of the Creative Commons Attribution (CC BY) license (https:// creativecommons.org/licenses/by/ $4.0 /)$.
Abstract: Alkali-activated mortars (AAMs) are developed incorporating binary/ternary combinations of industrial wastes comprising of fly ash class C (FA-C), fly ash class F (FA-F) and ground granulated blast furnace slag (GGBFS) with alkaline reagents and silica sand. The use of high calcium precursors, calcium-based powder form reagents, dry mixing method, and ambient curing with performance characterization based on chemical ratios and fracture properties are some novel aspects of the study. The mechanical (dry density, compressive strength, ultrasonic pulse velocity, elastic modulus, fracture/crack tip toughness and fracture energy), durability (shrinkage/expansion and mass change in water and ambient curing conditions, water absorption and freeze-thaw resistance) and microstructural (SEM/EDS and XRD analyses) characteristics of eight AAMs are investigated. The binary (FA-C + GGBFS) mortars obtained higher compressive strengths (between $35 \mathrm{MPa}$ and 42.6 MPa), dry densities (between $2032 \mathrm{~kg} / \mathrm{m}^{3}$ and $2088 \mathrm{~kg} / \mathrm{m}^{3}$ ) and ultrasonic pulse velocities (between $3240 \mathrm{~m} / \mathrm{s}$ and $4049 \mathrm{~m} / \mathrm{s}$ ) than their ternary (FA-C + FA-F + GGBFS) counterparts. The elastic modulus and fracture toughness for mortars incorporating reagent 2 (calcium hydroxide: sodium sulphate $=2.5: 1$ ) were up to 1.7 and five times higher than those with reagent 1 (calcium hydroxide: sodium metasilicate $=1: 2.5$ ). This can be attributed to the additional formation of C-S-H with C-A-S-H/N-C-A-S-H binding phases in mortars with reagent 2. Ternary mortars exhibited comparatively lower shrinkage/expansion and initial sorptivity indices than their binary counterparts due to the lower geopolymerisation potential of fly ash class $\mathrm{F}$ that facilitated the reduction of matrix porosity. All mortar specimens demonstrated $100 \%$ or more relative dynamic modulus of elasticity after 60 freeze-thaw cycles, indicating the damage recovery and satisfactory durability due to probable micro-level re-arrangement of the binding phases. This study confirmed the viability of producing cement-free AAMs with satisfactory mechanical and durability characteristics.

Keywords: alkali activated mortars; industrial wastes; powder form reagents; microstructure

\section{Introduction}

The alkali-activated materials or geopolymers are developed by enhancing the reaction process of industrial waste products or geological materials rich in silica and alumina content, such as fly ash, slag and metakaolin, through alkaline reagents, along with the incorporation of fine aggregates [1,2]. These cement-free alkali-activated materials, having better mechanical, durability and microstructural characteristics, are found to be more sustainable than the currently available low embodied blended cements and concretes in the market, incorporating industrial wastes and natural pozzolans such as fly ash, volcanic ash, volcanic pumice, and other underused natural materials [1-4]. This alkali activation technology also helps in reducing the disposal problems associated with municipal solid and ceramic tile wastes by utilizing them as precursors [5,6]. Understanding the influence of the ingredients of the alkali activation process on the mechanical, durability, and microstructural characteristics is crucial for developing alkali-activated materials from their in-situ applications in building and infrastructure industries [5-7]. 
The dependence of geopolymer matrix properties on components such as fly ash (FA), type of alkaline activator, activator to fly ash and sand (S) to fly ash (FA) ratios, temperature, and curing duration was assessed in a previous study [8]. The sand content is significant as it can affect matrix fracture toughness, pre-existing flaw size distribution and fibre-matrix interface properties. Therefore, this study evaluated the effect of sand size, sand content and water/geopolymer solids on geopolymer matrix characteristics. The Na-based multicomponent activator composed of $8.0 \mathrm{M}$ sodium hydroxide and Grade D sodium silicate solutions was used to prepare the geopolymer matrix. Sodium hydroxide and sodium silicate solutions were mixed with a $\mathrm{Na}_{2} \mathrm{SiO}_{3} / \mathrm{NaOH}$ mass ratio of 2.5 to prepare the $\mathrm{Na}-$ based activator. The matrix properties, such as the fresh matrix's workability, compressive strength, and fracture properties, including elastic modulus, fracture toughness, and crack tip toughness, were evaluated in this regard. The investigation results indicate that the workability decreased with increased sand sizes and sand contents in the mortar mixes. The compressive strength and elastic modulus of the plain geopolymer paste increased on the addition of sand regardless of its size and content [8]. Both the compressive strength and elastic modulus decreased with an increase in the water/geopolymer solids ratio. There is also a decrease in the matrix fracture toughness and crack tip toughness as the water/geopolymer solids ratio increases [8]. There is a 10-15\% improvement in the compressive strength of the matrix on an increase of $S / F A$ ratio from 0 to 0.3 , irrespective of the sand size. However, there is no significant increase in compressive strength on further increasing the S/FA ratio from 0.3 to 0.6 . There is an enhancement of $19-36 \%$ in the matrix's elastic modulus with the increase of the S/FA ratio from 0 to 0.3 . A further increase in the $\mathrm{S} / \mathrm{FA}$ ratio from 0.3 to 0.6 resulted in an additional improvement of elastic modulus in the range of $14-36 \%$. The effect of sand on the elastic modulus of the geopolymer matrix was more significant than the effect of sand on the elastic modulus of cement-based matrices. This more pronounced effect on geopolymer matrices is because of the significantly lower elastic modulus of geopolymer paste for the same compressive strength. There is an increase of $40-49 \%$ in the matrix fracture toughness on the increase in the sand/fly ash (S/FA) ratio from 0 to 0.3 . On further increment in S/FA ratio from 0.3 to 0.6 , there is an additional increase in the matrix fracture toughness from 16-33\%. This increase in matrix fracture toughness is because of an increase in energy consumption by the circuitous nature of the crack propagation path [8]. A similar trend was reported in other research studies with respect to the effect of sand on the matrix fracture toughness of cement-based matrices $[9,10]$. The matrix comprising coarse sand had a $7-22 \%$ lower matrix fracture toughness than the matrix containing fine sand at a constant S/FA ratio. This could be attributed to the fact that in a matrix comprised of coarse sand, the crack propagation is probably less circuitous due to a smaller number of coarse sand particles present in the matrix as when compared to fine sand of the same weight, as a result, consumes lesser energy for crack propagation when compared to a matrix containing fine sand. When the S/FA ratio was increased from 0 to 0.6 , irrespective of the sand size, there was a considerable increment in the crack tip toughness, which corresponds to a significant increase in matrix fracture toughness.

The influence of mix composition (proportion of precursors, concentration and silica modulus of alkali solutions, liquid to binder ratio) on fracture energy characteristics of GGBFS/FA-based concrete was investigated in a recent study [11]. The peak load and fracture energy determined from the three-point bending test increased with the increase in the alkali concentration, silica modulus, compressive strength, GGBFS/FA ratio, and decrease in liquid to binder ratio. Increases of $31.5 \%$ and $16.3 \%$ were observed in peak load and fracture energy, respectively, with increased alkali concentration from 3 to $5 \%$. Comparatively, a less significant increase $(4.4 \%)$ in peak load was noted with the increase in silica modulus. However, an increase of $22 \%$ was observed in fracture energy for the same increase in silica modulus. It was reported that with an increase in silica modulus, the shrinkage strains would increase, creating micro-cracks and resulting in strength reductions. 
However, these initial defects (micro-cracks) resulted in more energy absorption during crack propagation and improved the ductility of the matrix.

In another study, the effect of silica modulus in the reagent combination of sodium hydroxide (SH) with sodium silicate (SS) and proportions of precursors (GGBFS and FA-F) on matrix fracture characteristics (fracture toughness, crack-tip toughness and fracture energy) was investigated [12]. The fracture toughness increased with the increase in silica modulus from 0.5 to 1 and then decreased with a further increase in the silica modulus of the reagent. In addition, an increase in GGBFS content from 30\% to 50\% led to an increase in the compressive strengths and fracture toughness of geopolymer pastes. The highest values observed for fracture toughness at silica modulus of 0.5 were $0.36 \mathrm{MPa} \mathrm{m}{ }^{1 / 2}$ and $0.61 \mathrm{MPa} \mathrm{m}^{1 / 2}$, respectively, for mixes having 30\% and 50\% GGBFS content. The crack-tip toughness exhibited a similar trend to that for fracture toughness with silica modulus. The fracture energy decreased with the increase in GGBFS content and ranged between 6 to $15 \mathrm{~J} / \mathrm{m}^{2}$, which is comparatively lower than the fracture energy $\left(15\right.$ to $30 \mathrm{~J} / \mathrm{m}^{2}$ ) exhibited by cement-based materials. The lower fracture energy values for geopolymer pastes indicate that these pastes are more brittle than the cement-based materials with similar compressive strengths. The maximum values for fracture energy and compressive strengths with the lowest values for the porosity of GGBFS based geopolymer paste were obtained at silica modulus around 1 . The fracture characteristics reported were inferred to be related to the microstructural features and pore-structure of the pastes.

In another study, a comparison was made between geopolymer paste and concrete with OPC-based paste and concrete in terms of mechanical properties [13]. Precursor consisting of FA-F was used along with an alkaline solution-based reagent combination of $\mathrm{SH}$ and SS (Ms = 2) to develop a geopolymer binder. The type, shape and size of aggregates were kept the same for both geopolymer and OPC-based concrete. Therefore, the microstructure of the paste was mainly responsible for the difference in OPC and geopolymer concrete results. The geopolymer binder exhibited higher splitting tensile strength but lower elastic modulus and fracture energy than OPC paste. The crack propagation in geopolymer paste was less circuitous (consumes less energy) due to the round shape of FA particles than angular-shaped cement particles. A lower characteristic length (one-third of OPC-based paste) indicating higher brittleness of geopolymer paste because of their highly crosslinked structure at the micro-level was noted compared to its OPC counterpart.

A recent study has evaluated the effect of using two different types of solution-based reagents and the addition of sand on the mechanical performance of strain hardening geopolymer composites (SHGC) [14]. Two geopolymer binders were developed using metakaolin $(\mathrm{MK})$ as a precursor and two multi-component solution-based reagents. The first multi-component reagent consisted of SH and SS solutions, while the second multicomponent reagent was composed of potassium hydroxide $(\mathrm{KH})$ and potassium silicate (KS) solutions. A fine quartz sand ( $50 \%$ by mass of MK) and PVA fibres $2 \%(v / v)$ were incorporated into the binder compositions to produce SHGC. The potassium-activated paste obtained higher crack tip toughness $(6.32 \mathrm{~N} / \mathrm{m})$ than sodium-activated paste $(2.63 \mathrm{~N} / \mathrm{m})$ due to its lower elastic modulus and higher intrinsic toughness because of its porous microstructure, leading to longer crack propagation paths. Both mortars (potassium and sodium activated) observed higher elastic modulus values than their paste counterparts. The increase in elastic modulus with the incorporation of sand was more pronounced in sodium-activated mortars owing to its higher density and lower porosity at the paste level [14].

A novel one-part ambient temperature cured strain hardening geopolymer composite (SHGC) was developed in a research study [15]. This SHGC production consisted of a dry mixing process of source materials comprising of slag $(50 \% w / w)$ and fly-ash $(50 \% w / w)$ with a small quantity of powdered based anhydrous sodium metasilicate as an activator, thus avoiding the need of using a large amount of commonly used alkaline solution-based activators and eliminating the necessity for heat curing. The ambient temperature curing resulted in enhanced chemical bond strength $\left(G_{d}\right)$ when typical slag was used in the 
geopolymer composite. An opposite trend was observed when gypsum-free slag was used as one of the geopolymer precursors in composite production. This difference in the chemical bond strength parameter of the composites could be due to the different microstructures being developed because of different slag types and curing conditions. The ambient cured geopolymer composite's mechanical performance parameters (compressive and tensile strength) are comparable to conventional strain-hardening cementitious composites M 45 (SHCC M45). The developed composites in this research exhibited lower global warming potential in terms of $76 \%$ lower carbon dioxide emissions and $36 \%$ lower embodied energy than typical SHCC M45. Besides, the geopolymer composites developed in this study can be classified as lightweight composites. They exhibited an average density of $1849 \mathrm{~kg} / \mathrm{m}^{3}$, unlike conventional SHCC M45 composites with an average density of $2077 \mathrm{~kg} / \mathrm{m}^{3}$ [15].

The various parameters or ingredients involved in the design aspects of AAMs also influence their durability characteristics. The influence of precursors (fly ash and slag) in geopolymer concrete on shrinkage/expansion characteristics compared to OPC concretes/mortars was investigated in a recent study [16]. The shrinkage strains were higher in fly ash/slag concrete than OPC concrete on the first day of exposure to drying conditions. However, the shrinkage strains $(290 \mu \mathrm{m} / \mathrm{m})$ were similar in both concrete types after 28 days of drying exposure [16]. Another study reported that shrinkage strains were reduced in fly ash/slag pastes with the incorporation of fly ash up to $50 \%$ and increased with $70 \%$ replacement of slag with fly ash. It was attributed to the different binding gels being formed with the change in the proportions of the precursors [17].

The replacement $(5 \%, 10 \%$ and $15 \%)$ of slag by $\mathrm{MgO}$ (hydromagnesite burnt at $550{ }^{\circ} \mathrm{C}$ ) in another study resulted in the reduction in shrinkage strains by $40 \%, 57 \%$ and $77 \%$ compared to $0 \% \mathrm{MgO}-$ slag binder after 90 days of drying conditions [18]. The combined use of shrinkage-reducing admixtures and expansive agents were found to be effective in reducing shrinkage strains to the level of Portland cement-based mortars $(1000 \mu \mathrm{m} / \mathrm{m})$ at 150 days [19]. In another research, shrinkage strains increased with paper sludge content in the geopolymer mix comprising slag and pre-treated paper sludge, with values between $0.14 \%$ for the lowest paper sludge content to $0.39 \%$ for the highest paper sludge content at 90 days. This was attributed to the increase in calcium carbonate content associated with the increase in paper sludge. On the contrary, the water absorption decreased with an increase in paper sludge content in the mix. The values ranged from $4.8 \%$ (for the lowest amount of paper sludge) to $4.1 \%$ (for the highest amount of paper sludge) at 14 days. The paper sludge partially acted as filler material and reduced the pore size and porosity [20]. The replacement of FA by palm oil fuel ash (POFA) in ternary blends of FA, POFA and slag was found to enhance the pore structure and reduce the drying shrinkage strains [21].

The effect of curing conditions on the shrinkage of fly ash-slag geopolymer concrete was evaluated in another research. It was inferred that a minimum of three days curing at $40{ }^{\circ} \mathrm{C}$ was required to bring the shrinkage strains to the level specified by Eurocode 2 for OPC-based concretes. However, curing at $80{ }^{\circ} \mathrm{C}$ for one day effectively lowered the shrinkage strains to meet the standard requirements [22]. Lower values of drying shrinkage strains were noted for steam cured geopolymer (fly ash, slag and glass powder) mortar specimens compared to their water cured counterparts [23]. The effect of heat curing and ambient curing of alkali-activated slag (AASC) and fly ash concrete (AAFC) on drying shrinkage at early (dried after $72 \mathrm{~h}$ in lime water) and later ages (dried after 90 days in lime water) was investigated in another study. The shrinkage strains in case of early age drying were found to be above $1000 \mu \varepsilon$ for AASC. However, the volumetric stability of AASC was significantly enhanced and reduced the shrinkage strains by at least two-thirds at later ages. For heat cured AASC specimens, shrinkage strains were reduced by more than $75 \%$ at later ages. The shrinkage strains of AAFC were observed to be of lower magnitude than AASC and were noted to decrease further with an increase in sodium oxide concentration [24].

The freeze-thaw resistance of alkali-activated mortars (GGBFS based) samples was investigated in another study for 150 freeze-thaw cycles with a cycle period of $12 \mathrm{~h}\left(-20^{\circ} \mathrm{C}\right.$ to $+5{ }^{\circ} \mathrm{C}$ ). The mortars (with and without air-entraining admixture) with lower activator 
concentration of activators (8\%) suffered superficial damage after 50 cycles, while others showed no deterioration. Lower reductions in strength and elastic modulus (up to 50\% lower) were observed for mortars incorporating air-entraining admixtures (AEA) than those without AEA at the end of 150 cycles. This was attributed to the denser and more compact microstructure of the mortars with AEA than without AEA, which led to lower water penetration and lesser saturation and freezing [25].

Wardhono et al. [26] investigated the variation in water permeability and ultrasonic pulse velocity of low calcium fly ash geopolymer (FAGP) and alkali-activated slag (AAS) concretes with time up to 540 days. In the water permeability test, both capillary absorption and the applied pressure contribute to the rate of water flow. The AAS concrete showed an increase of water permeability index (WPI) with age but was classified as low water permeable concrete at all ages as the water permeability index did not exceed $1.3 \times 10^{-7} \mathrm{~m}^{3} / \sqrt{ } \mathrm{min}$. The FAGP concrete had a significantly higher WPI than AAS up to 90 days and was well above the minimum limit of low water permeable concrete. However, it dramatically decreased by 180 days and further reduced at later ages, having a lower value than AAS concrete at 360 and 540 days. This is again consistent with ongoing geopolymerization and in agreement with the corresponding ultrasonic pulse velocity (UPV) and strength data [26]. The water absorption rate was higher in mixes incorporating FA, and GGBFS than the GGBFS alone mixes in a recent study. The highest sorptivity indices were observed for the mixtures using FA as the only precursor. The increase of permeable voids on the incorporation of FA in the mix composition was inferred to be the reason for higher sorptivity indices. Lower UPV values were also observed for mixes with increased FA content due to FA's lower activation potential [27]. Generally, the pulse velocity values represent the uniformity and the presence of defects in the microstructure and pore structure, such as voids and cracks [28], which directly influence concrete permeation properties. The FAGP concrete displayed an increase of UPV with age, while for AAS, there was a fall in UPV from 3.91 to 3.62 between 28 and 540 days. The standard pulse velocity of PC concrete generally falls in the range of 3.5 to $4.5 \mathrm{~km} / \mathrm{s}$, which can be categorized as being in good condition, which implies that the concrete is free from any large voids or cracks that may affect long-term structural reliability. Interestingly, while AAS exhibited decreased UPV with time, all the data points were well above $3.5 \mathrm{~km} / \mathrm{s}$. The FAGP concrete was identified as poor-quality concrete with UPV values below $3 \mathrm{~km} / \mathrm{s}$ at 56 days; however, it obtained $3.5 \mathrm{~km} / \mathrm{s}$ UPV by 540 days. Overall, the data from the permeability properties would further suggest ongoing geopolymerization and concurrent gel formation resulting in a denser microstructure and pore-structure for FAGP concrete over the 540 days. However, the permeation properties would indicate no improvement in the AAS concrete beyond 90 days [26].

Another durability concern is the efflorescence phenomenon when free alkali present in pore solution reacts with humidity of air containing $\mathrm{CO}_{2}$ to form white deposits characteristic of carbonate compound $\left(\mathrm{Na}_{2} \mathrm{CO}_{3}\right.$ or $\left.\mathrm{K}_{2} \mathrm{CO}_{3}\right)$ at the surface of the concrete structure [29]. Allahverdi et al. [30] investigated sodium oxide concentration's effect on the efflorescence formation in the hardened paste of alkali-activated blast furnace slag. The severity of efflorescence intensified with an increase in the concentration of sodium oxide. This confirms the relationship between the severity of the efflorescence and the concentration of sodium oxide. A relatively high sodium oxide concentration could be partially in excess and results in some non-reacted sodium hydroxide in the material that can be easily leached out. The leached sodium hydroxide reacts with atmospheric carbon dioxide to produce sodium carbonate, resulting in efflorescence formation [30].

The literature review suggests that there has been limited research on the mechanical, durability and microstructural characteristics of alkali-activated mortars (AAMs) developed using powder form reagents under ambient conditions, especially suitable for producing fibre-reinforced engineered cementitious composites (ECCs). Moreover, there is also a lack of a research database on the performance evaluation of AAMs with high calcium-based precursors and reagents incorporating silica sand as fine aggregate. 
This paper addresses the above-mentioned research gaps by presenting a study on the development and comprehensive evaluation of novel silica sand incorporated high calcium based AAM mixes. The influence of mix ingredients such as two types of calcium-based powder form reagents (reagent 1: calcium hydroxide + sodium metasilicate and reagent 2: calcium hydroxide + sodium sulphate) and binary/ternary combinations/proportions of high calcium precursors (fly ash class $\mathrm{C}$, fly ash class $\mathrm{F}$ and ground granulated blast furnace slag) with the fundamental chemical ratios $\left(\mathrm{SiO}_{2} / \mathrm{Al}_{2} \mathrm{O}_{3}, \mathrm{Na}_{2} \mathrm{O} / \mathrm{SiO}_{2}, \mathrm{CaO} / \mathrm{SiO}_{2}\right.$, and $\mathrm{Na}_{2} \mathrm{O} / \mathrm{Al}_{2} \mathrm{O}_{3}$ ) present in the precursors/reagents on mechanical, durability and microstructural characteristics has been investigated.

The novelties of this paper are in the development and performance evaluation of ambient cured AAMs, using high calcium precursors in binary/ternary combinations, the combination of calcium-based powder form reagents (compared to commonly used heat cured-low calcium precursors-sodium based reagents counterparts), fine silica sand, and the one-part dry mixing method. In addition, the development of AAMs with adequate fracture properties for producing novel flowable fibre reinforced alkali-activated engineered cementitious composites (AAECCs) having strain hardening, multiple microcracking, strength and durability characteristics comparable to traditional cement-based ECCs. The characterization of the performance of AAMs based on fundamental chemical ratios present in the precursors and reagents is also an important aspect of the study. This research also contributes to the improvement of commercially viable user-friendly dry mixing powdered-based technology, which can eliminate the use of the large quantity of corrosive solution-based reagents and heat curing, facilitating pre-packaged production. The findings of this research will certainly benefit engineers and researchers to understand the properties of developed AAMs and further develop AAM-based concrete and composites for construction applications.

\section{Experimental Program, Materials, and Methods}

The experimental program involved a comprehensive evaluation of geopolymer/alkaliactivated mortars developed from the optimized paste mix compositions produced by the authors [31,32], incorporating a constant amount of silica sand. The performance of the developed mortars has been assessed in terms of mechanical (dry density, compressive strength, elastic modulus, fracture toughness, crack tip toughness and fracture energy), durability properties (drying shrinkage in water and ambient/air curing regimes, sorptivity and freeze-thaw resistance) and microstructural characteristics through scanning electron microscopy (SEM), coupled with energy-dispersive X-ray spectroscopy (EDS) and X-ray diffraction (XRD). The influence of the addition of silica sand on shrinkage/expansion and mass change characteristics of mortars are also compared to their paste (without silica sand) counterparts.

\subsection{Materials}

High calcium fly-ash class C (FA-C), low calcium fly-ash class F (FA-F), ground granulated blast furnace slag (GGBFS), silica sand (maximum particle size $600 \mu$ ), as well as two types of powder-based reagents were used to develop AAM mixes using the dry mixing technique [31,32]. The precursors (FA-C, FA-F and GGBFS) were provided by $\mathrm{CRH}$, Canada and silica sand was procured from Bell \& MacKenzie Co. Ltd, Canada. Reagent 1 was composed of a combination of calcium hydroxide $\left(\mathrm{Ca}(\mathrm{OH})_{2}\right)$ and sodium meta-silicate $\left(\mathrm{Na}_{2} \mathrm{SiO}_{3} \cdot 5 \mathrm{H}_{2} \mathrm{O}\right)$, having a modular ratio $\left(\mathrm{SiO}_{2} / \mathrm{Na}_{2} \mathrm{O}\right)$ of 1.0. The constituents of the reagent 2 were calcium hydroxide $\left(\mathrm{Ca}(\mathrm{OH})_{2}\right)$ and sodium sulphate $\left(\mathrm{Na}_{2} \mathrm{SO}_{4}\right)$. The specific gravities of $\mathrm{Ca}(\mathrm{OH})_{2}, \mathrm{Na}_{2} \mathrm{SiO}_{3} .5 \mathrm{H}_{2} \mathrm{O}$ and $\mathrm{Na}_{2} \mathrm{SO}_{4}$ were $2.24,1.81$ and $2.70 \mathrm{~g} / \mathrm{cm}^{3}$, respectively. The alkalinity in terms of $\mathrm{pH}$ values of $\mathrm{Ca}(\mathrm{OH})_{2}, \mathrm{Na}_{2} \mathrm{SiO}_{3} \cdot 5 \mathrm{H}_{2} \mathrm{O}$ and $\mathrm{Na}_{2} \mathrm{SO}_{4}$ were 12.4-12.6, 14 and 7, respectively. All the reagents were of lab-grade quality procured from Westlab, Canada., having a purity of 95-100\%. Type GU-general use cement (supplied by CRH, Canada) was also used for producing control mortar mixes. A polycarboxylate ether-based superplasticizer (supplied by GCP Applied Technologies, USA) having a $\mathrm{pH}$ 
of 6 , a specific gravity of $1.06 \mathrm{~g} / \mathrm{cm}^{3}$ and an approximate solid content of $40 \%$ was used as a high range water reducer admixture (HRWRA) to produce flowable mortar mixes. The chemical compositions obtained through X-ray fluorescence spectrometer analysis and the physical properties of SCMs, and cement are presented in Table 1. The grain size distribution of the SCMs, cement and silica sand are presented in Figure 1.

Table 1. Chemical composition and physical characteristics of fly ash-class C, fly ash-class F, GGBFS, and cement.

\begin{tabular}{ccccc}
\hline Chemical Composition (\%) & FA-C & FA-F & GGBFS & Cement \\
\hline $\mathrm{SiO}_{2}$ & 36.53 & 55.66 & 35.97 & 19.35 \\
$\mathrm{Al}_{2} \mathrm{O}_{3}$ & 18.26 & 22.09 & 9.18 & 5.31 \\
$\mathrm{Fe}_{2} \mathrm{O}_{3}$ & 5.66 & 4.26 & 0.50 & 3.10 \\
$\mathrm{CaO}$ & 20.97 & 7.97 & 38.61 & 62 \\
$\mathrm{MgO}$ & 5.08 & 1.16 & 10.99 & 3 \\
$\mathrm{~K}_{2} \mathrm{O}$ & 0.68 & 1.49 & 0.36 & - \\
$\mathrm{Na}_{2} \mathrm{O}$ & 4.04 & 4.10 & 0.28 & 0.23 \\
$\mathrm{MnO}$ & 0.03 & 0.03 & 0.25 & - \\
$\mathrm{TiO}_{2}$ & 1.26 & 0.61 & 0.39 & - \\
$\mathrm{P}_{2} \mathrm{O}_{5}$ & 0.96 & 0.43 & 0.01 & - \\
$\mathrm{LOI}$ & 2.18 & 1.05 & 0.74 & 2.40 \\
\hline Physical Properties & FA-C & FA-F & GGBFS & Cement \\
\hline Density $\left(\mathrm{g} / \mathrm{cm}^{3}\right)$ & 2.61 & 2.02 & 2.87 & 3.15 \\
Retained on $45 \mu(\%)$ & $<5$ & $<10$ & $<5$ & $<10$ \\
Blaine fineness $\left(\mathrm{m}^{2} / \mathrm{kg}\right)$ & 315 & 306 & 489.30 & 410 \\
\hline
\end{tabular}

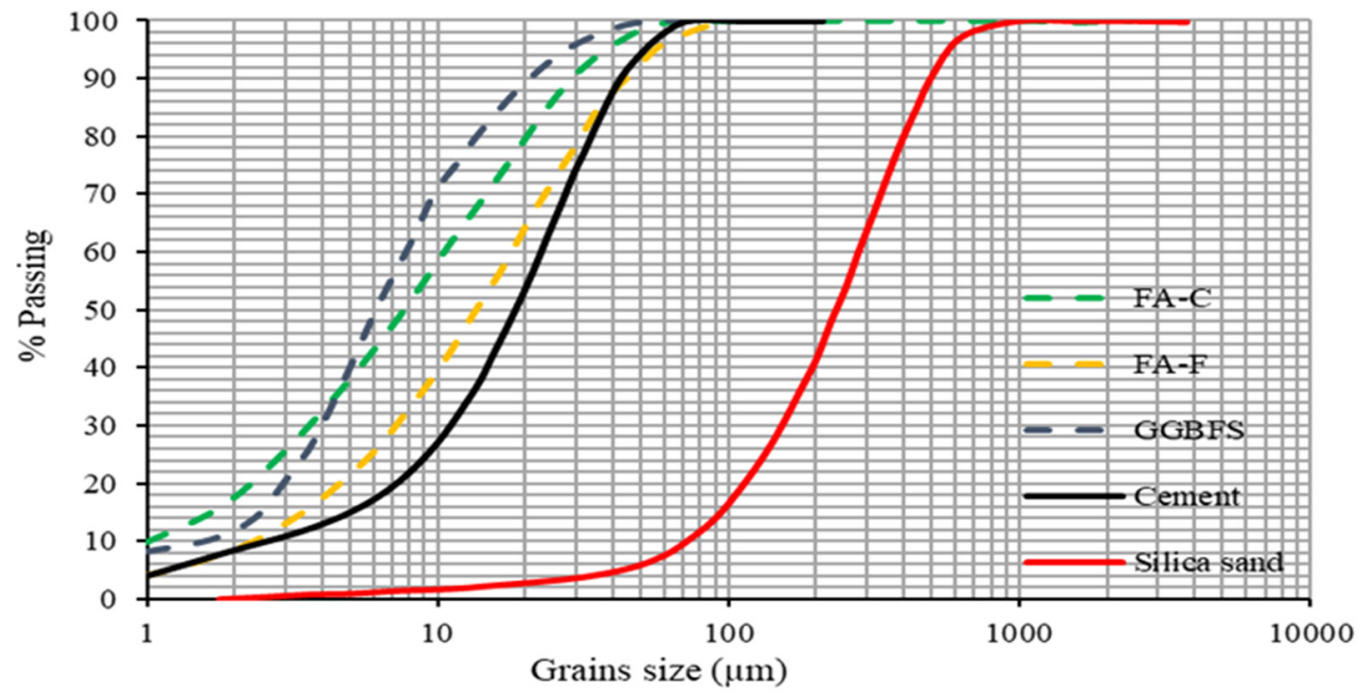

Figure 1. Grain size distribution of SCMs, cement and silica sand.

\subsection{Mix Proportions}

The eight optimized alkali-activated paste binders resulting from four binary/ternary combinations of SCMs and two powder-based reagents having two different dosages from authors' research [31,32] were used to develop AAMs with a constant amount of silica sand. The objective was to achieve comparable fresh, and rheological characteristics to the control cement-based mortar $\left(\mathrm{FP}_{\mathrm{C}} \mathrm{M}\right)$, with a high volume of fly ash previously developed for producing fibre-reinforced engineered cementitious composites [33,34]. The mix proportions for one-part AAMs and control mortar are presented in Table 2. The total fly ash content varied from $50 \%$ to $60 \%$, and the amount of ground granulated blast furnace slag (GGBFS) varied from $40 \%$ to $50 \%$ by mass of the total binder content, similar to the fly ash and cement content in the control mortar as indicated in Table 2. Two 
dosages/combinations of powder-based reagents were used. A constant amount of silica sand ( $30 \%$ by mass of total binder content) was added to the paste mix when it obtained the desired fluidity. The low quantity of sand to develop AAMs was selected as per the previously established engineered cementitious and geopolymer composites (mortars reinforced with fibres) based on fracture mechanics to facilitate lower crack-tip toughness and multiple micro-cracking of the specimens under loading $[8,33,34]$. The use of low sand to binder ratio (up to 0.30 ) ensured adequate workability for uniform fibre distribution, inducing strain hardening and multiple micro-cracking characteristics $[8,33,34]$. The water to binder ratio varied from 0.35 to 0.375 to achieve a minimum slump flow diameter of 150 $\mathrm{mm}$. The dosage of HRWRA was kept constant as it is acidic and should not act differently for varying mix compositions due to its different alkalinity.

Table 2. Mix proportions for one-part alkali-activated and control mortars.

\begin{tabular}{|c|c|c|c|c|c|c|c|c|c|c|}
\hline Mix Designation & Total SCMs (Binder *) & Cement & FA-C & FA-F & GGBFS & $\begin{array}{c}\text { Reagent } \\
\text { Type }\end{array}$ & Reagent/Binder & $\begin{array}{l}\text { Silica } \\
\text { Sand }\end{array}$ & \multicolumn{2}{|c|}{ Water/Binder HRWRA ** } \\
\hline \multicolumn{11}{|c|}{ Alkali Activated Mortars (AAMs)-CS: Binary and CFS: Ternary } \\
\hline CSM1 & 1 & 0 & 0.55 & 0 & 0.45 & 1 & 0.09 & 0.3 & 0.35 & 0.02 \\
\hline CSM1N & 1 & 0 & 0.50 & 0 & 0.50 & 1 & 0.09 & 0.3 & 0.35 & 0.02 \\
\hline CFSM1 & 1 & 0 & 0.25 & 0.35 & 0.40 & 1 & 0.09 & 0.3 & 0.35 & 0.02 \\
\hline CFSM1N & 1 & 0 & 0.25 & 0.25 & 0.50 & 1 & 0.09 & 0.3 & 0.35 & 0.02 \\
\hline CSM2 & 1 & 0 & 0.55 & 0 & 0.45 & 2 & 0.12 & 0.3 & 0.375 & 0.02 \\
\hline CSM2N & 1 & 0 & 0.50 & 0 & 0.50 & 2 & 0.12 & 0.3 & 0.375 & 0.02 \\
\hline CFSM2 & 1 & 0 & 0.25 & 0.35 & 0.40 & 2 & 0.12 & 0.3 & 0.375 & 0.02 \\
\hline CFSM2N & 1 & 0 & 0.25 & 0.25 & 0.50 & 2 & 0.12 & 0.3 & 0.375 & 0.02 \\
\hline \multicolumn{11}{|c|}{ Control Mortar } \\
\hline $\mathrm{FP}_{\mathrm{C}} \mathrm{M}$ & 1 & 0.45 & 0 & 0.55 & 0 & N.A. & NA. & 0.36 & 0.27 & 0.006 \\
\hline
\end{tabular}

All numbers are mass ratios of the binder; ${ }^{*}$ Binder denotes supplementary cementitious materials (SCMs) and Portland cement (PC); C: FA-C, F: FA-F, S: GGBFS, N denotes mixes with equal mass of fly ash (class C + class F) and GGBFS; The numeric value in the mix designation denotes reagent type; ${ }^{* *}$ HRWRA: Poly-carboxylate ether-based superplasticizer.

The reagent component and the initial chemical ratios in the mix compositions are presented in Table 3. The reagent 1 has a reagent component ratio (calcium hydroxide to sodium metasilicate) of 1:2.5, while reagent 2 has a reagent component ratio (calcium hydroxide to sodium sulphate) of 2.5:1. These component ratios were superior performing in terms of compressive strength from authors' research on AABs [31,32].

Table 3. Reagent component and chemical ratios in mix compositions.

\begin{tabular}{|c|c|c|c|c|c|c|c|c|}
\hline \multirow{2}{*}{$\begin{array}{c}\text { Mix } \\
\text { Designation }\end{array}$} & \multirow{2}{*}{$\begin{array}{l}\text { Reagent } \\
\text { Type }\end{array}$} & \multirow{2}{*}{$\begin{array}{l}\text { Reagent } \\
\text { Component } \\
\text { Ratio }\end{array}$} & \multicolumn{4}{|c|}{$\begin{array}{l}\text { Chemical Ratios } \\
\text { (SCMs + Reagents) }\end{array}$} & \multirow{2}{*}{$\begin{array}{c}\text { 28-Day } \\
\text { Compressive } \\
\text { Strength (MPa) }\end{array}$} & \multirow{2}{*}{$\begin{array}{l}\text { 28-Day } \\
\text { Density } \\
\left(\mathrm{kg} / \mathrm{m}^{3}\right)\end{array}$} \\
\hline & & & $\mathrm{SiO}_{2} / \mathrm{Al}_{2} \mathrm{O}_{3}$ & $\mathrm{Na}_{2} \mathrm{O} / \mathrm{SiO}_{2}$ & $\mathrm{CaO} / \mathrm{SiO}_{2}$ & $\mathrm{Na}_{2} \mathrm{O} / \mathrm{Al}_{2} \mathrm{O}_{3}$ & & \\
\hline CSM1 & 1 & $1: 2.5$ & 2.62 & 0.09 & 0.84 & 0.23 & 42.6 & 2088 \\
\hline CSM1N & 1 & $1: 2.5$ & 2.71 & 0.08 & 0.87 & 0.23 & 35.0 & 2075 \\
\hline CFSM1 & 1 & $1: 2.5$ & 2.75 & 0.08 & 0.59 & 0.22 & 40.4 & 2030 \\
\hline CFSM1N & 1 & $1: 2.5$ & 2.86 & 0.07 & 0.69 & 0.21 & 34.0 & 2010 \\
\hline CSM2 & 2 & $2.5: 1$ & 2.56 & 0.14 & 1.02 & 0.35 & 41.2 & 2042 \\
\hline CSM2N & 2 & $2.5: 1$ & 2.64 & 0.13 & 1.02 & 0.35 & 35.8 & 2032 \\
\hline CFSM2 & 2 & $2.5: 1$ & 2.69 & 0.12 & 0.73 & 0.32 & 42.0 & 1983 \\
\hline CFSM2N & 2 & $2.5: 1$ & 2.80 & 0.12 & 0.84 & 0.33 & 38.1 & 2055 \\
\hline $\mathrm{FP}_{\mathrm{C}} \mathrm{M}$ & - & - & 2.70 & 0.06 & 0.82 & 0.16 & 43.5 & 1937 \\
\hline
\end{tabular}

SCMs: Supplementary cementitious materials; In mix designation—numerical value denotes reagent type, C: FA-C, F: FA-F, S: GGBFS, N denotes mixes with equal mass of fly ash (class $\mathrm{C}+$ class F) and GGBFS.

The fundamental chemical ratios, in terms of silicon oxide to aluminium oxide, sodium oxide to silicon oxide, calcium oxide to silicon oxide and sodium oxide to aluminium oxide, were evaluated from the XRF results of the precursors/source materials and the chemical composition of the reagents. These chemical ratios were found to fall within the range of AAMs with adequate workability and strength characteristics, as per recent studies on fly ash and slag-based mortars [1,2]. 


\subsection{Mixing, Casting, and Curing of Specimens}

The aluminosilicate-rich materials (binder constituents) and the reagents required for each mix composition were weighed per the proportions given in Tables 2 and 3. The reagent components were first mixed thoroughly to form a multi-component reagent/activator. This multi-component reagent/activator was then added to the rigorously blended binder constituents. The complete binder system was then dry mixed for about $3 \mathrm{~min}$ in a shear mixer. After 3 min of dry mixing, two-third of the required water was gradually added to the mix. The HRWRA mixed with the remaining amount of water was gradually added to make the paste flowable for the addition of silica sand as per the proportions given in Table 2. The incorporation of sand was followed once the paste became flowable so that the sand did not hinder the initial alkali activation reactions taking place. After sand addition, the remaining HRWRA mixed with water was added gradually to the mortar. The total mixing procedure lasted about $12-15 \mathrm{~min}$.

At least 12 cube specimens with dimensions of $50 \mathrm{~mm} \times 50 \mathrm{~mm} \times 50 \mathrm{~mm}$ were prepared for each mix composition for compressive strength testing as per ASTM C109/C109M16 [35]. Three mortar beam specimens with dimensions of $50.8 \mathrm{~mm} \times 76.2 \mathrm{~mm} \times 355.6 \mathrm{~mm}$ per mix composition were prepared for fracture energy characteristics and ultra-sonic pulse velocity (UPV) measurements in compliance with previous studies [36,37]. A notch of depth equal to half the beam depth was created to ensure the crack occurs and propagates from the centre of the beam specimens. Prisms with dimensions ( $25 \mathrm{~mm} \times 25 \mathrm{~mm} \times 285 \mathrm{~mm}$ ) were prepared for shrinkage/expansion and mass change investigations according to ASTM C490/490M-17 [38], ASTM C596-17 [39] and ASTM C157/157M-17 [40]. The cylinders $(\varnothing 100 \mathrm{~mm} \times 200 \mathrm{~mm})$ were cast for conducting the sorptivity measurements on the disc specimens $(\varnothing 100 \mathrm{~mm} \times 50 \mathrm{~mm})$ cut out of cylinders at the testing days following ASTM C1585-13 [41]. The beam specimens $(50.8 \mathrm{~mm} \times 76.2 \mathrm{~mm} \times 355.6 \mathrm{~mm})$ were prepared for testing resistance to freeze-thaw cycles according to ASTM C666-15 [42]. All the specimens were kept in the curing room/chamber maintained at a temperature of $23 \pm 3{ }^{\circ} \mathrm{C}$ and $95 \pm 5 \%$ relative humidity $(\mathrm{RH})$, unless other conditions were required, as per the test methods. The moulds were de-moulded $24 \mathrm{~h}$ after casting and were kept in the curing chamber until the testing days.

\subsection{Test Methods}

The compressive strength test at 28/56 days was conducted on cube specimens according to ASTM C109/C109M-16 [35]. A three-point bending test as shown in Figure 2a,b on the single edge notched beam specimens $(50.8 \mathrm{~mm} \times 76.2 \mathrm{~mm} \times 355.6 \mathrm{~mm})$ was conducted to evaluate the fracture properties of the mortars, including elastic modulus $\left(E_{m}\right)$, fracture toughness $\left(K_{m}\right)$, fracture energy $\left(\mathrm{G}_{\mathrm{f}}\right)$ and crack tip toughness $\left(J_{\text {tip }}\right)$. A constant span to beam depth ratio $(l / d)$ of 4 and an initial notch depth to beam depth ratio $(a / d)$ of 0.5 was implemented for all the specimens. The displacement control rate of $0.18 \mathrm{~mm} / \mathrm{min}$ was used to ensure that the maximum load for any specimen occurs within the initial 30-60 s in compliance with the previous study guidelines [36]. The elastic modulus is computed as per Equation (1) [37].

$$
E_{m}=\frac{0.413 P_{i}}{\delta_{i}}\left[\frac{l^{3}\left(1+\frac{5 \omega l}{8 P_{i}}\right)}{4 b d^{3}\left(1-\frac{a}{d}\right)^{3}}+\frac{1.17 l}{1.68 b d\left(1-\frac{a}{d}\right)}\right]
$$

where $P_{i}$ is the arbitrary load level in the initial (linear) portion of the load-deflection plot; $\delta_{i}$ is its corresponding deflection; $l, b$, and $d$ are the span, width, and depth of the specimen, respectively; $a$ is the initial notch depth, and $\omega$ is the self-weight of the specimen per unit length. 


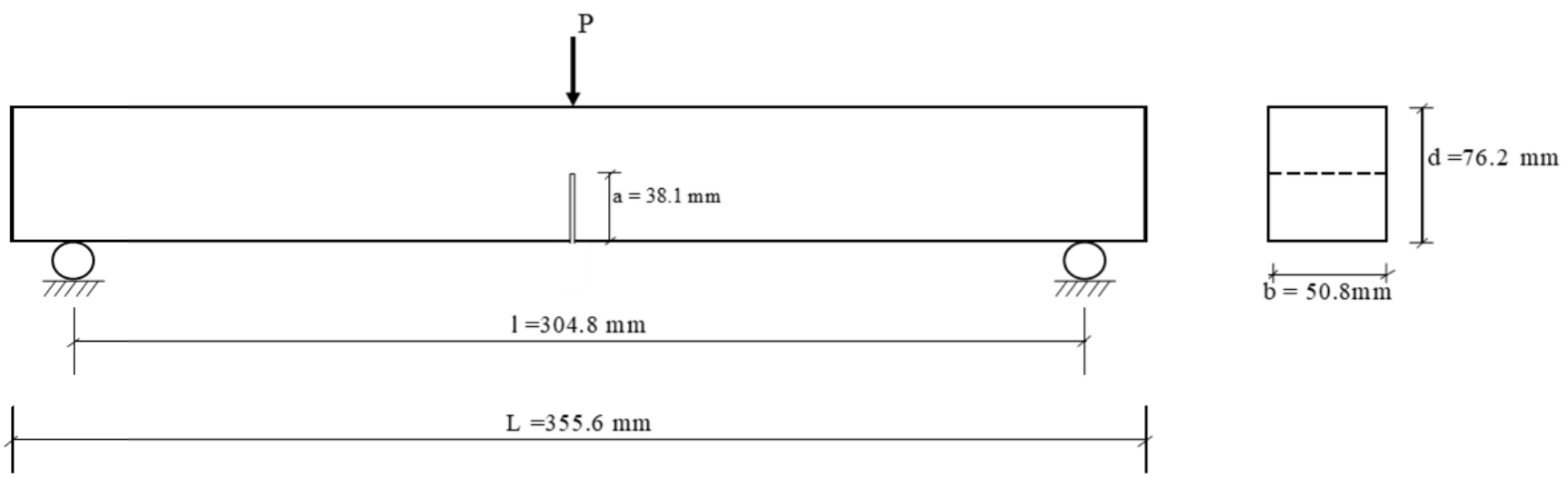

(a)

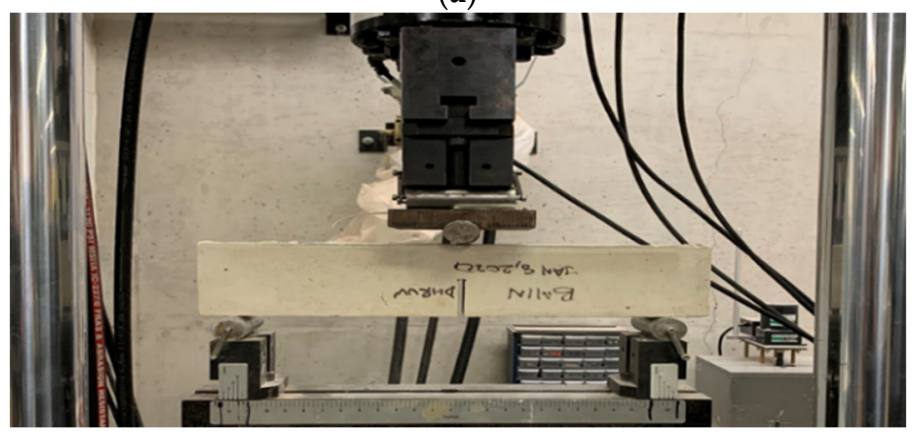

(b)

Figure 2. (a): Schematic sketch of three-point bending test. (b): Test setup of three-point bending test.

The matrix fracture toughness is determined using Equation (2).

$$
K_{m}=\sigma_{n} \sqrt{a_{e}} \mathrm{Y}(a)
$$

where, $\sigma_{n}=\frac{6 M}{b d^{2}}$, in which $M=\left[P_{\max }+\left(\frac{\omega l}{2}\right)\right]\left(\frac{l}{4}\right) ; \alpha_{e}=$ effective notch depth, which can be derived from Equation (1) by substituting the $P_{i}$ and $\delta_{i}$ by the peak load $\left(P_{\text {max }}\right)$, and its corresponding deflection $\left(\delta_{p}\right)$; and $\mathrm{Y}(a)$ is the correction factor given by Equation (3) in which $\alpha=a_{e} / d$ :

$$
\mathrm{Y}(a)=\frac{1.99-a(1-a)\left(2.15-3.93 a+2.70 a^{2}\right)}{(1+2 a)(1-a)^{1.5}}
$$

Crack tip toughness $\left(J_{\text {tip }}\right)$ is calculated as indicated in Equation (4):

$$
J_{\text {tip }}=\frac{\left(K_{m}\right)^{2}}{E_{m}}
$$

Fracture energy $\left(G_{F}\right)$ is defined as the energy consumed during the creation of one unit area of the crack and can be determined in compliance with RILEM TC50-FMC [13] by Equation (5):

$$
G_{F}=\frac{\left(W_{0}+m g \delta_{0}\right)}{A_{l i g}}
$$

where $W_{0}$ is the area under the load-displacement curve of the three-point bending test; $m$ is the mass of the beam specimen between the supports as illustrated in Figure $2 \mathrm{a}, \mathrm{b} ; \mathrm{g}$ is the acceleration due to gravity $\left(9.8 \mathrm{~m} / \mathrm{s}^{2}\right) ; \delta_{0}$ is the final displacement at failure and $A_{\text {lig }}$ is the area of the ligament $\left(\mathrm{m}^{2}\right)$.

The drying shrinkage test was conducted in compliance with ASTM C490/490M17 [38], ASTM C596-17 [39] and ASTM C157/157M-17 [40]. Eight prismatic specimens with dimensions $25 \mathrm{~mm} \times 25 \mathrm{~mm} \times 285 \mathrm{~mm}$ were prepared for each mix composition 
and de-moulded after $24 \mathrm{~h}$. The specimens were stored in air-tight plastic bags until being de-moulded. After demoulding, initial mass and length readings were taken with a digital comparator, having an accuracy of up to $0.001 \mathrm{~mm}$ and considered a reference. The length and mass change readings were taken at 1/7/28/56/90 days for the specimens in two curing regimes: water storage and air/ambient storage, in compliance with ASTM C157/157M-17 [40]. In the water curing regime, specimens were kept immersed in water through the days of testing. For the air curing regime, after an initial curing period of 28 days in water immersion, four samples per mix composition were shifted to the drying room maintained at a relative humidity of $50 \pm 4 \%$ and a temperature of $23 \pm 2{ }^{\circ} \mathrm{C}$.

The water absorption rate (sorptivity index) was determined for the geopolymer/control mortars in compliance with ASTM C1585-13 [41]. For each mix composition (detailed in Table 2), six specimens were prepared by cutting $\varnothing 100 \mathrm{~mm} \times 50 \mathrm{~mm}$ discs from the exterior parts of $\varnothing 100 \mathrm{~mm} \times 200 \mathrm{~mm}$ cylinders. The specimens were cured for 21 days in airtight plastic bags at an ambient temperature of $23 \pm 2{ }^{\circ} \mathrm{C}$ and $95 \pm 5 \%$ relative humidity (RH). After the curing period, the specimens were placed inside an oven maintained at a temperature of $50 \pm 2{ }^{\circ} \mathrm{C}$ for three days and later transferred to a sealable air-tight container for the next 15 days before initiating the water absorption process. Following the ASTM guidelines, specimens were kept submerged in water to a depth of $2 \pm 1 \mathrm{~mm}$ from their bottom surface. An aluminium tape sealed the sides of the specimens, and the top surface of specimens was covered with plastic wrap to prevent the evaporation of water, as illustrated in Figure 3. The sorptivity test was performed at the age of 39 days, consisting of 21 days of curing period and 18 days of specimens' preparation. The sorptivity index is based on the rate of water penetration through unsaturated concrete by capillary suction. Thus, the specimens' mass was recorded at standard time intervals during testing, and mass change was evaluated to determine the initial and secondary sorptivity indices.

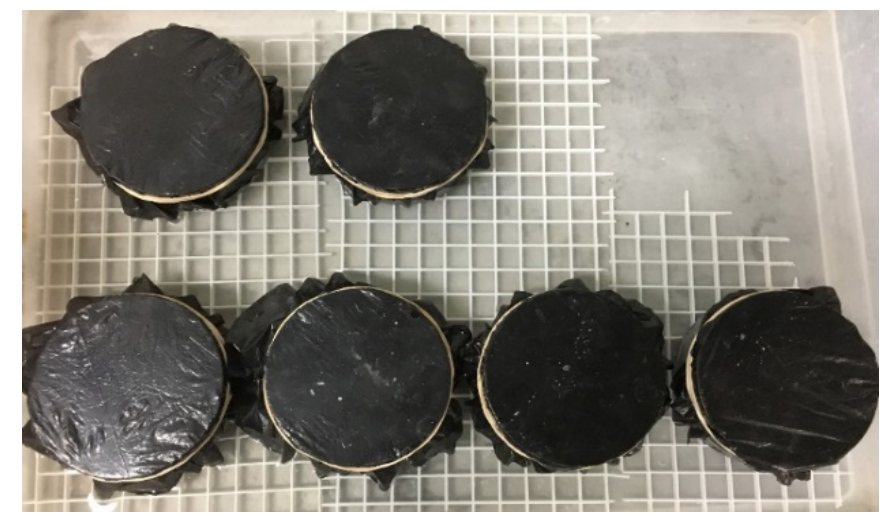

Figure 3. Sorptivity test setup.

A set of three prisms $(50.8 \mathrm{~mm} \times 76.2 \mathrm{~mm} \times 355.6 \mathrm{~mm})$ from each mortar mixes was produced to conduct freeze-thaw tests. In addition, a set of prisms from the control mortar were prepared for the comparison of test results. The prisms were cured in plastic bags at $95 \pm 5 \%$ relative humidity $(\mathrm{RH}), 23 \pm 2{ }^{\circ} \mathrm{C}$ for up to 14 days, and then placed into the freeze-thaw chamber as shown in Figure 4. During testing, prisms were subjected to 60 alternate freeze-thaw cycles as per ASTM C666-15 "Procedure A" [42]. Due to the lack of resonance frequency measurement, which is recommended by ASTM C666-15 [42], ultrasonic pulse velocity (UPV) measurement was used in this study as used in other research studies to measure the damage induced to prisms by freeze-thaw cycles [43-45]. It should be noted that mass change and relative dynamic modulus of elasticity (RDME) based on changes in UPV measurements (time and velocity) were calculated at 0, 30 and 
60 cycles. Relative dynamic modulus along the transverse direction (Width $=50.8 \mathrm{~mm}$ ) of the beam specimen was calculated using Equation (6):

$$
P_{C}=\frac{T_{c}^{2}}{T^{2}} \times 100
$$

where $P_{C}$ and $T_{\mathcal{C}}$ represents the relative dynamic modulus of elasticity and fundamental transverse frequency, respectively, after ' $c$ ' cycles of freezing and thawing, $T$ denotes the fundamental transverse frequency after 0 cycles of freezing and thawing.

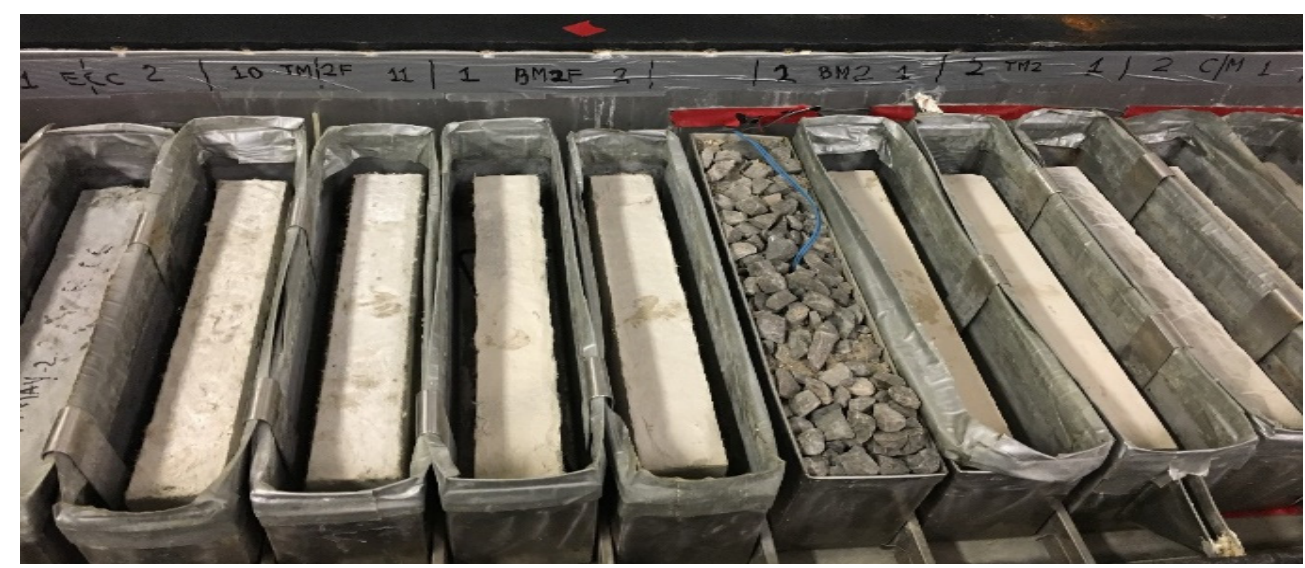

Figure 4. Test setup for freeze-thaw resistance.

The SEM and EDS analyses were conducted on mortars to determine the reaction products. The specimens were taken from the core of the failed compression test cubes at 28 days for SEM/EDS analysis. The specimens were grounded and softly polished with sandpaper down to $30 \mu \mathrm{m}$. A gold coating was performed on the specimens to make the surface conductive. The fracture surface was studied using both the secondary electrons (SE) and the backscattered electron (BES) at $20 \mathrm{kV}$. The specimens' morphology was studied at $100 \times(100 \mu \mathrm{m})$, and the reaction products assessment was conducted at $2000 \times(10 \mu \mathrm{m})$.

X-ray diffraction analysis was performed to identify the mineral phases present in the mortar mixes and validate the SEM/EDS results. The specimen preparation for performing XRD analysis consisted of grounding the specimen taken from the core of the failed compression cubes. The grounded specimen was passed through a 200-mesh sieve. A Bruker D8 Endeavor diffractometer equipped with Cu X-ray source and operating at $40 \mathrm{kV}$ and $40 \mathrm{~mA}$; range $5-70 \operatorname{deg} 2^{\circ}$; step size $0.02 \mathrm{deg} 2^{\circ}$; time per step $0.5 \mathrm{sec}$; fixed divergence slit, angle 0.30 ; sample rotation $1 \mathrm{rev} / \mathrm{sec}$ was used to identify the mineral phases using PDF4/Minerals ICDD database.

\section{Results and Discussions}

\subsection{Mechanical Characteristics of Mortars}

The mechanical properties of the developed mortars are evaluated in terms of dry density, compressive strength, UPV, elastic modulus, fracture toughness, crack-tip toughness, and fracture energy. All the mixes were designed to obtain a minimum slump flow spread of $150 \mathrm{~mm}$ to ensure their suitability for producing engineered cementitious and geopolymer composites with good workability as per the existing studies $[8,33,34]$.

\subsubsection{Dry Density, Compressive Strength and UPV}

Dry density, compressive strength and UPV of AAM mixes are presented in Table 4. All the mixes satisfied the criteria for structural concrete as per ACI 318 [46], exhibiting 28-day compressive strengths ranging from $34 \mathrm{MPa}$ to $43.5 \mathrm{MPa}$. The binary mix CSM1 obtained the highest 28-day compressive strength of $42.6 \mathrm{MPa}$ amongst all AAMs, as noted in Table 4 . From 28 days to 56 days, $8 \%$ to $15 \%$ increase in compressive strength was 
observed in AAMs due to the ongoing formation of reaction products with time. The binary mortar systems obtained higher compressive strengths ( $35 \mathrm{MPa}$ to $42.6 \mathrm{MPa}$ ), dry densities $\left(2032 \mathrm{~kg} / \mathrm{m}^{3}\right.$ to $\left.2088 \mathrm{~kg} / \mathrm{m}^{3}\right)$ and UPV $(3240 \mathrm{~m} / \mathrm{s}$ to $4049 \mathrm{~m} / \mathrm{s})$ than their ternary counterparts due to the additional CSH binding phases/gels formation, which further densified the matrix. The mixes having equal content of fly ash and GGBFS (CSM1N, CSM2N, CFSM1N and CFSM2N) exhibited up to $18 \%$ lower compressive strengths than the other AAMs (CSM1, CSM2, CFSM1 and CFSM2). This can be attributed to the excessive calcium or GGBFS content in the mix, resulting in the formation of expansive products leading to strength reductions. However, mixes incorporating reagent 2 obtained up to $12 \%$ higher 28-day compressive strengths due to their higher $\mathrm{CaO} / \mathrm{SiO}_{2}$ than those with reagent 1 . It can be inferred that a threshold exists for calcium or GGBFS content in the alkali-activated systems that govern the strength.

Table 4. Hardened state characteristics of mortars.

\begin{tabular}{|c|c|c|c|c|c|}
\hline \multirow{2}{*}{ Mix Designation } & \multirow{2}{*}{$\begin{array}{c}\text { Density }\left(\mathrm{kg} / \mathrm{m}^{3}\right) \\
\text { 28-Day }\end{array}$} & \multicolumn{2}{|c|}{ Compressive Strength- $\mathrm{f}_{\mathrm{cu}}(\mathrm{MPa})$} & \multirow{2}{*}{$\frac{f_{c u}(\% \text { Increase })}{56-\text { Day }}$} & \multirow{2}{*}{$\frac{\mathrm{UPV}(\mathrm{m} / \mathrm{s})}{28-D a y}$} \\
\hline & & 28-Day & 56-Day & & \\
\hline CSM1 & $2088 \pm 45$ & $42.6 \pm 1.92$ & $49.0 \pm 1.78$ & 15.0 & $3240 \pm 65$ \\
\hline CSM1N & $2075 \pm 38$ & $35.0 \pm 1.43$ & $41.5 \pm 1.56$ & 18.6 & $3502 \pm 73$ \\
\hline CSM2 & $2042 \pm 52$ & $41.2 \pm 1.78$ & $48.5 \pm 1.84$ & 17.7 & $3746 \pm 78$ \\
\hline CSM2N & $2032 \pm 49$ & $35.8 \pm 1.74$ & $40.0 \pm 1.45$ & 11.7 & $4049 \pm 84$ \\
\hline CFSM1 & $2030 \pm 32$ & $40.4 \pm 1.65$ & $45.2 \pm 1.64$ & 11.9 & $3320 \pm 68$ \\
\hline CFSM1N & $2010 \pm 24$ & $34.0 \pm 1.59$ & $38.1 \pm 1.55$ & 12.1 & $3367 \pm 70$ \\
\hline CFSM2 & $1983 \pm 18$ & $42.0 \pm 1.84$ & $46.4 \pm 1.85$ & 10.5 & $3205 \pm 59$ \\
\hline CFSM2N & $2055 \pm 42$ & $38.1 \pm 1.53$ & $41.2 \pm 1.65$ & 8.1 & $3607 \pm 72$ \\
\hline $\mathrm{FP}_{\mathrm{C}} \mathrm{M}$ & $1937 \pm 15$ & $43.5 \pm 1.83$ & $50.0 \pm 1.86$ & 14.9 & $4133 \pm 92$ \\
\hline
\end{tabular}

Linear correlations (UPV $=90.573 \mathrm{f}_{\mathrm{cu}}$ and dry density $=51.358 \mathrm{f}_{\mathrm{cu}}$ ) were observed between compressive strength and UPV as well as between dry density and UPV of mortars at 28 days with root mean square values of 0.98 and 0.99 , respectively, as presented in Figure 5. These linear relationships indicate that the measurement of UPV (a non-destructive technique) can give some idea about the strength, density and durability of the AAMs.

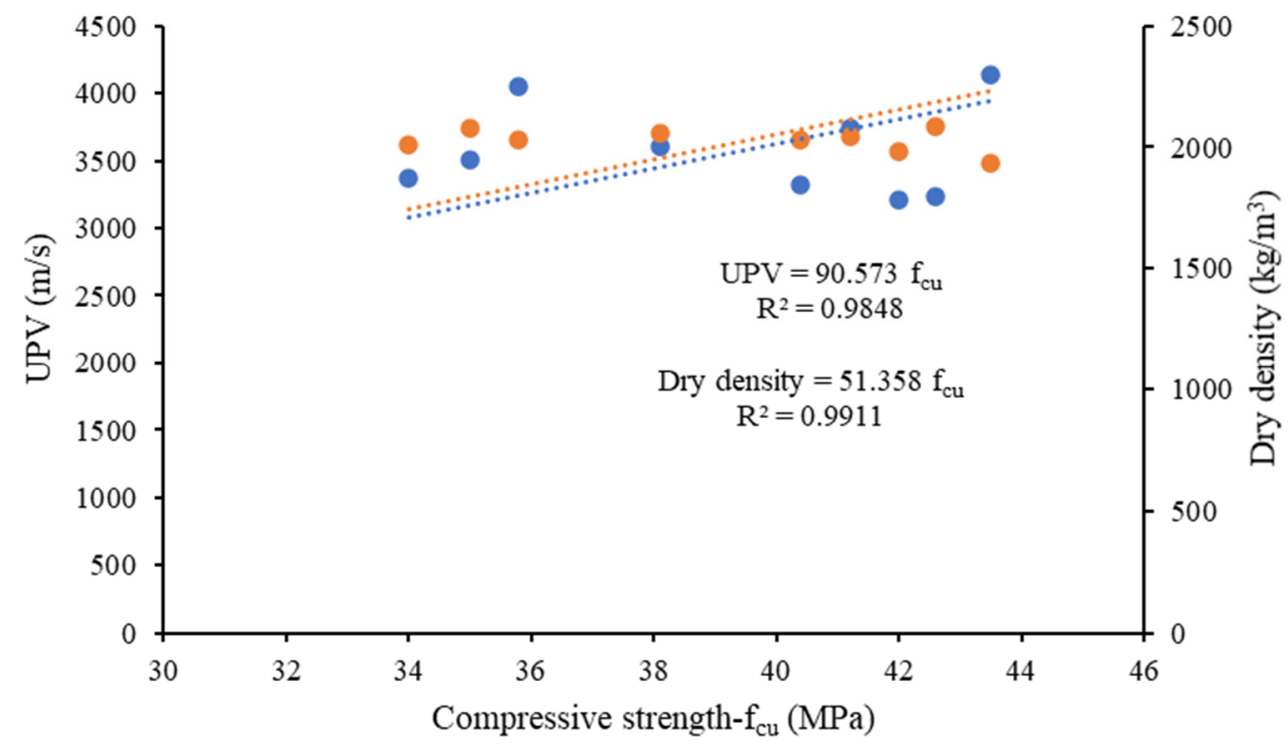

Figure 5. Relationships between UPV, compressive strength and dry density at 28 days.

\subsubsection{Fracture Characteristics of Mortars}

The mortar fracture characteristics were evaluated using the load-displacement curves depicted in Figure 6 and the effective crack model developed in a previous study [47]. It is 
evident from Figure 6 that the peak load and the displacement development are influenced by the mix compositions. The fracture properties of the mortars in terms of $E_{m}$ Equation (1), $K_{m}$ Equation (2), $J_{\text {tip }}$ Equation (4) and $G_{f}$ Equation (5) are presented in Table 5. The values of $E_{m}, K_{m}$, and $J_{\text {tip }}$ are used to compare the different mix compositions and to characterize the probable strain hardening/multiple cracking behaviour in fibre-reinforced composites. The 28-day peak load obtained from the fracture energy test using notched beams made of different mortar compositions is found to be directly proportional to the compressive strength, as per the linear equation (Peak load $=0.007 \mathrm{f}_{\mathrm{cu}} ; \mathrm{R}^{2}=0.90$ ) shown in Figure 7 .

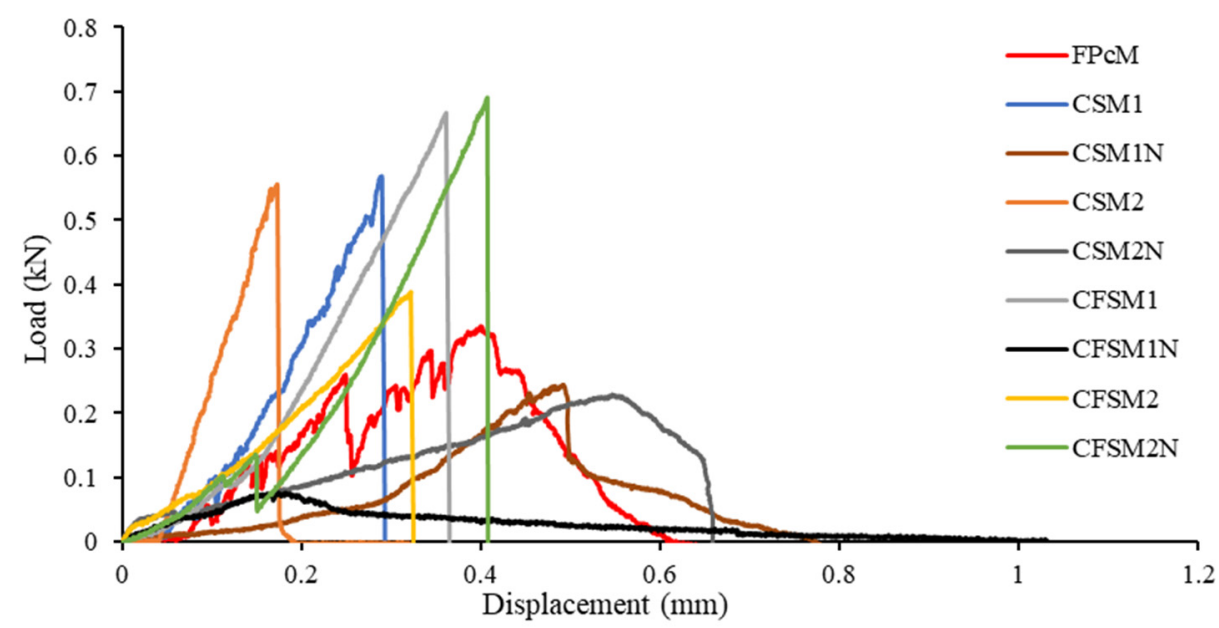

Figure 6. Load-mid span displacement responses of specimens from fracture energy tests.

Table 5. Fracture properties and compressive strength of mortars at 28 days.

\begin{tabular}{|c|c|c|c|c|c|c|c|}
\hline $\begin{array}{c}\text { Mix } \\
\text { Designation }\end{array}$ & Peak Load (kN) & $\begin{array}{c}\text { Peak } \\
\underset{(\mathrm{mm})}{\text { Displacement }}\end{array}$ & $\begin{array}{c}\text { Fracture } \\
\text { Energy (N/m) }\end{array}$ & $\underset{(\mathrm{GPa})}{\text { Elastic }} \underset{\mathrm{Modulus}}{\left(E_{m}\right)}$ & $\begin{array}{c}\text { Fracture } \\
\text { Toughness }\left(K_{m}\right) \\
\left(\mathrm{MPa} \mathrm{m}^{1 / 2}\right)\end{array}$ & $\begin{array}{c}\text { Crack Tip } \\
\text { Toughness }\left(J_{t i p}\right) \\
\left(\mathrm{J} / \mathrm{m}^{2}\right)\end{array}$ & $\begin{array}{c}\text { 28-Day } \\
\text { Compressive } \\
\text { Strength (MPa) }\end{array}$ \\
\hline $\mathrm{FP}_{\mathrm{C}} \mathrm{M}$ & 0.33 & 0.62 & $95.28 \pm 2.86$ & $1.14 \pm 0.06$ & $0.188 \pm 0.007$ & $10 \pm 0.34$ & $43.5 \pm 1.83$ \\
\hline CSM1 & 0.57 & 0.29 & $64.67 \pm 2.26$ & $1.74 \pm 0.09$ & $0.242 \pm 0.008$ & $34 \pm 1.35$ & $42.6 \pm 1.92$ \\
\hline CSM1N & 0.24 & 0.78 & $73.44 \pm 2.12$ & $0.542 \pm 0.03$ & $0.203 \pm 0.008$ & $76 \pm 2.92$ & $35 \pm 1.43$ \\
\hline CSM2 & 0.55 & 0.19 & $37.98 \pm 1.16$ & $1.77 \pm 0.09$ & $0.282 \pm 0.014$ & $45 \pm 1.86$ & $41.2 \pm 1.78$ \\
\hline CSM2N & 0.23 & 0.66 & $94.49 \pm 3.02$ & $0.757 \pm 0.03$ & $0.229 \pm 0.011$ & $69 \pm 3.11$ & $35.8 \pm 1.74$ \\
\hline CFSM1 & 0.66 & 0.36 & $73.14 \pm 2.12$ & $1.42 \pm 0.073$ & $0.415 \pm 0.019$ & $121 \pm 5.32$ & $40.4 \pm 1.65$ \\
\hline CFSM1N & 0.08 & 1.03 & $38.46 \pm 1.27$ & $0.64 \pm 0.03$ & $0.078 \pm 0.004$ & $9 \pm 0.35$ & $34 \pm 1.59$ \\
\hline CFSM2 & 0.39 & 0.32 & $47.36 \pm 1.42$ & $1.128 \pm 0.05$ & $0.297 \pm 0.013$ & $78 \pm 3.34$ & $42 \pm 1.84$ \\
\hline CFSM2N & 0.68 & 0.41 & $78.35 \pm 2.65$ & $1.065 \pm 0.04$ & $0.393 \pm 0.015$ & $145 \pm 6.53$ & $38.1 \pm 1.53$ \\
\hline
\end{tabular}

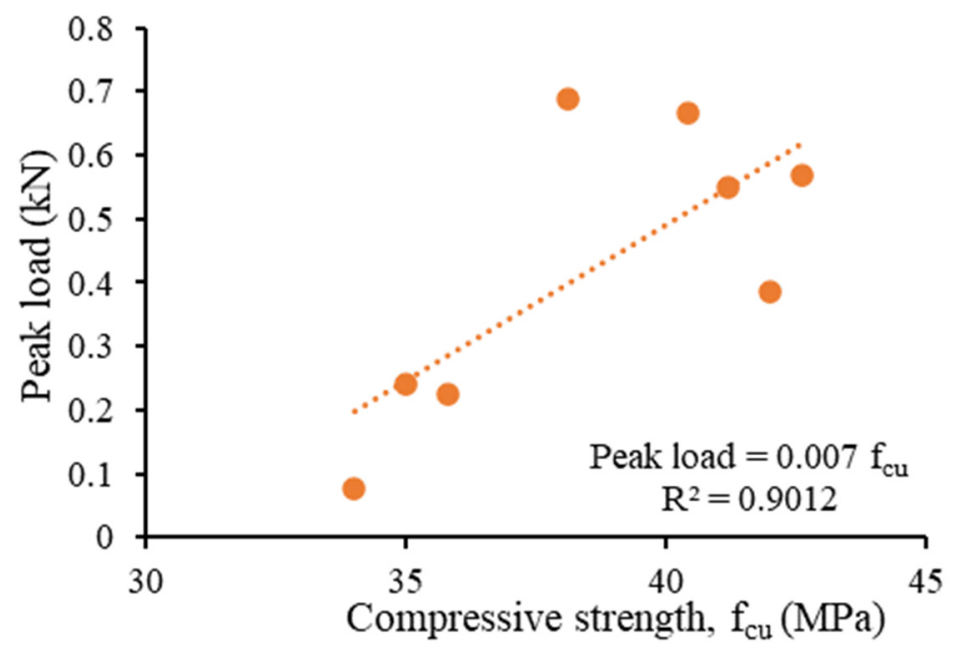

Figure 7. Cube compressive strength versus peak load obtained from fracture energy test. 
The elastic modulus values varied from $0.542 \mathrm{GPa}$ to $1.74 \mathrm{GPa}$ for binary mortars and from $0.64 \mathrm{GPa}$ to $1.42 \mathrm{GPa}$ for ternary mortars. A correlation was observed between the square root of compressive strengths and the elastic modulus of the mortar specimens, as represented by the equation $\left(E_{m}=0.1847 \mathrm{f}^{\prime} \mathrm{c}^{0.5}\right)$ noted in Figure $8 \mathrm{a}$, with a correlation coefficient $\mathrm{R}^{2}$ value of 0.89 . A similar trend was seen in previous studies $[14,15,36,48-51]$, as indicated in Figure $8 \mathrm{a}$, with a correlation coefficient of 0.95 . The elastic modulus values for mortar compositions incorporating reagent 2 were up to 1.7 times higher than those with reagent 1 , as indicated in Table 5 . This can be attributed to the formation of additional C-S-H gel observed in the SEM/EDS analysis of the mix compositions with reagent 2, due to the high calcium content in the system. Higher fracture toughness $\left(K_{m}\right)$ values varying from $0.229 \mathrm{MPa} \mathrm{m}^{1 / 2}$ to $0.393 \mathrm{MPa} \mathrm{m}^{1 / 2}$ were also observed in the mixes with reagent 2 , due to their high compressive strengths.

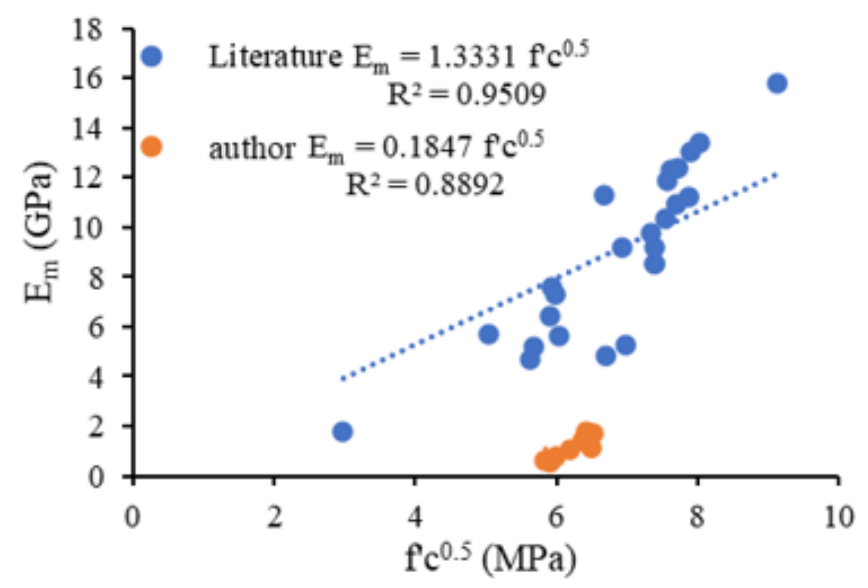

(a)

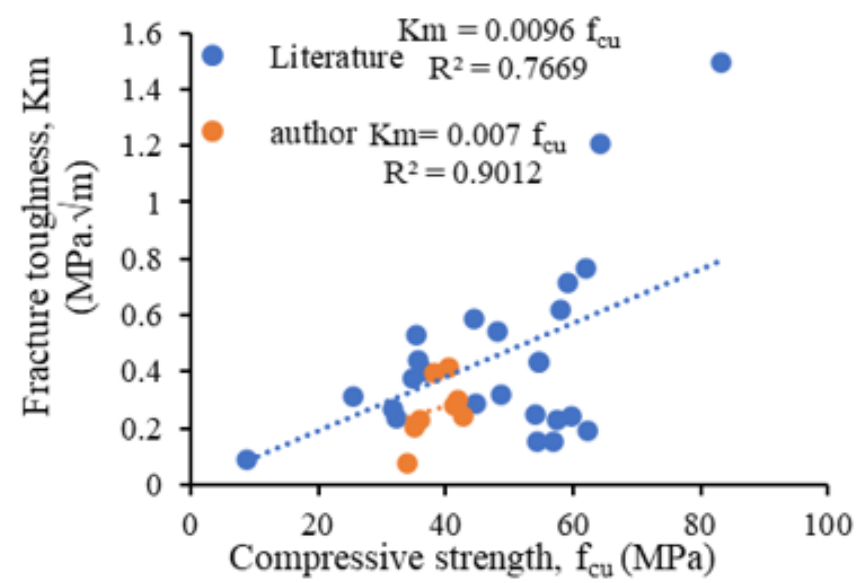

(b)

Figure 8. (a) Square root of compressive strength versus elastic modulus, (b) Compressive strength versus fracture toughness.

A linear correlation between compressive strength and fracture toughness is observed (Figure $8 b)$ in the current $\left(K_{m}=0.007 \mathrm{f}_{\mathrm{cu}}\right.$ with $\left.\mathrm{R}^{2}=0.90\right)$ and previous $\left(K_{m}=0.0096 \mathrm{f}_{\mathrm{cu}}\right.$ with $\mathrm{R}^{2}=0.77$ ) research studies $[14,15,36,48-51]$. The fracture toughness and crack tip toughness of ternary mixes were found to be up to 1.7 and 3.6 times higher, respectively, than their binary counterparts owing to the formation of a combination of binding phases (N-A-S-H/N-C-A-S-H and C-A-S-H). This led to the circuitous path for crack propagation and hence, producing higher fracture and crack tip toughness. However, lower fracture 
and crack tip toughness were observed for ternary mix CFSM1N due to its lowest peak load (fracture energy test) and compressive strength.

The fracture energy was also correlated to the fracture toughness of the mortar specimens by the equation $\left(G_{f}=216.2 K_{m} ; R^{2}=0.87\right)$ shown in Figure $9 \mathrm{~b}$. The fracture energy of mortars varied from $37.98 \mathrm{~N} / \mathrm{m}$ to $94.49 \mathrm{~N} / \mathrm{m}$, with the highest value being almost equal to the control mortar $\left(\mathrm{FP}_{\mathrm{C}} \mathrm{M}\right)$, as indicated in Table 5. A linear correlation $\left(E_{m}=3.9779 K_{m}\right.$; $\mathrm{R}^{2}=0.87$ ) is also found to exist between the elastic modulus and fracture toughness of the mortars (Figure 9a). This proves the general hypothesis that the higher compressive strength resulted in higher fracture toughness and elastic modulus, as can be inferred from the linear correlations found in this study $\left(E_{m}=0.1847 \mathrm{f}^{\prime} \mathrm{c}^{0.5}\right.$ and $\left.K_{m}=0.007 \mathrm{f}_{\mathrm{cu}}\right)$.

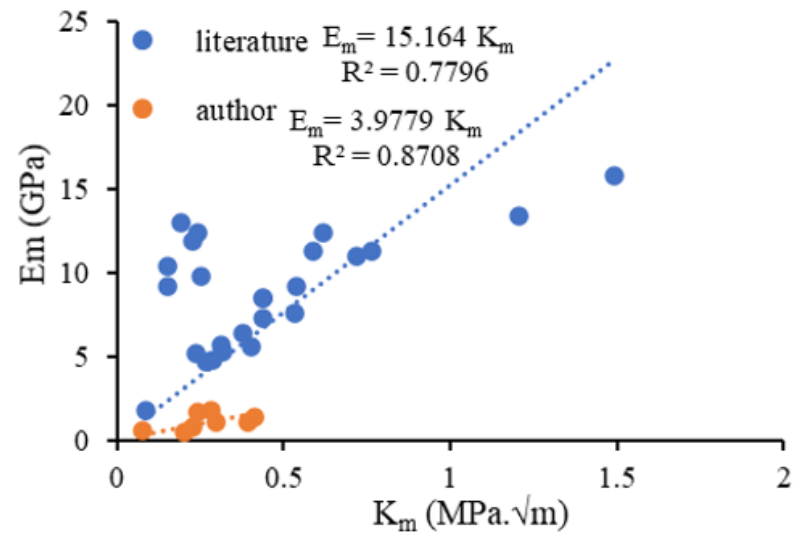

(a)

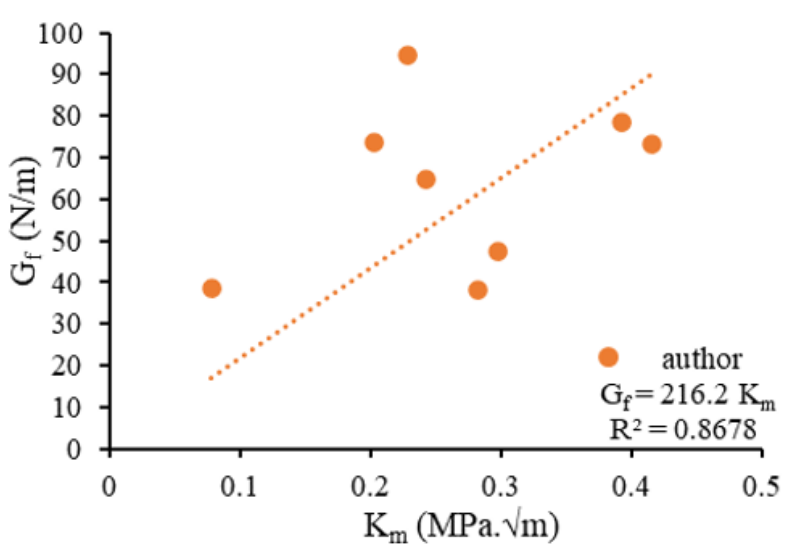

(b)

Figure 9. Three-point bending (a) Fracture toughness versus elastic modulus, (b) Fracture toughness versus fracture energy.

The existing literature and present study observed the existence of linear correlations between the different fracture characteristics (peak load, compressive strength, elastic modulus, fracture toughness, fracture energy and crack-tip toughness). However, these correlations do not reveal the significant interdependence between the different fracture properties of varying mix compositions, as evident from comparatively lower $\mathrm{R}^{2}$ values. These correlations have been well established for cement-based materials. However, more micromechanics-based investigations are needed on high calcium alkali-activated materials with a wide range of mix compositions to generate more data for establishing such correlations. This is because of the formation of crystalline C-S-H gels for cement-based mortars, in contrast to the formation of a combination of amorphous (N-C-A-S-H/N-A$\mathrm{S}-\mathrm{H})$ and crystalline (C-A-S-H/C-S-H) products in AAM mixes in varying proportions depending on mix designs, as confirmed by the SEM/EDS and XRD analyses.

\subsection{Durability Characteristics}

The durability properties of the mortar mixes have been characterized by drying shrinkage in two curing regimes (water and ambient/air storage), rate of water absorption in terms of sorptivity indices and the freeze-thaw resistance of specimens at 0,30 and 60 cycles.

\subsubsection{Shrinkage/Expansion}

The length (shrinkage/expansion) and mass change of specimens made of pastes and silica sand incorporated mortars in water and air curing regimes were determined at 1, 7, 28,56 and 90 days. The length and mass change results at 56 and 90 days are presented in Table 6 for different mortars and respective paste compositions. 
Table 6. Length and mass change of pastes and mortars in water curing regime.

\begin{tabular}{|c|c|c|c|c|c|c|c|c|c|c|c|}
\hline \multirow{2}{*}{$\begin{array}{l}\text { Paste } \\
\text { Mixes }\end{array}$} & \multicolumn{2}{|c|}{ Length Change (\%) } & \multicolumn{2}{|c|}{ Mass Change (\%) } & \multirow{2}{*}{$\begin{array}{l}\text { 56-Day Comp. } \\
\text { Strength (MPa) }\end{array}$} & \multirow{2}{*}{$\begin{array}{l}\text { Mortar } \\
\text { Mixes }\end{array}$} & \multicolumn{2}{|c|}{ Length Change (\%) } & \multicolumn{2}{|c|}{ Mass Change (\%) } & \multirow{2}{*}{$\begin{array}{l}\text { 56-Day Comp. } \\
\text { Strength (MPa) }\end{array}$} \\
\hline & 56-Day & 90-Day & 56-Day & 90-Day & & & 56-Day & 90-Day & 56-Day & 90-Day & \\
\hline $\mathrm{FP}_{\mathrm{C}}$ & 0.42 & 0.20 & 4.13 & 4.20 & 50.5 & $\mathrm{FP}_{\mathrm{C}} \mathrm{M}$ & 0.59 & 0.55 & 1.69 & 1.75 & 50 \\
\hline CS1 & -0.77 & -0.63 & 0.26 & -3.5 & 55.4 & CSM1 & -0.58 & -0.41 & 0.22 & 0.48 & 49 \\
\hline CS1N & -0.54 & -0.48 & 0.12 & 0.02 & 47 & CSM1N & -0.56 & -0.35 & 0.23 & 0.54 & 41.5 \\
\hline CS2 & -0.22 & -0.2 & 0.59 & 0.64 & 64.2 & CSM2 & 0.35 & 0.45 & 1.86 & 2.41 & 48.5 \\
\hline CS2N & 0 & 0.18 & 1.95 & 2.05 & 49 & CSM2N & -0.15 & -0.15 & 0.71 & 0.80 & 40 \\
\hline CFS1 & -0.44 & -0.30 & 0.93 & -3.66 & 54.2 & CFSM1 & -0.39 & -0.22 & 0.69 & 1.24 & 45.2 \\
\hline CFS1N & -0.05 & -0.06 & 1.66 & 1.53 & 44.4 & CFSM1N & -0.26 & -0.18 & 0.99 & 0.85 & 38.11 \\
\hline CFS2 & -0.06 & -0.04 & 0.78 & 0.82 & 56 & CFSM2 & 0.13 & 0.32 & 0.64 & 0.55 & 46.4 \\
\hline CFS2N & -0.18 & 0.06 & 0.43 & 0.56 & 46.5 & CFSM2N & 0.13 & 0.29 & 1.70 & 1.35 & 41.2 \\
\hline
\end{tabular}

Negative (-) sign in length and mass change indicates shrinkage and mass loss, and positive length and mass change denotes expansion and mass gain.

The variation in shrinkage/expansion strains for mortar specimens with time in water (represented by solid lines) and air/ambient curing regimes (indicated by dotted lines) are presented in Figure 10a,b. In general, mortar mixes with reagent 2 demonstrated expansion at all ages, while their counterpart mortars incorporating reagent 1 exhibited shrinkage. This trend can be attributed to more crystalline cementitious binding phases in mixes with reagent 2 than with reagent 1 (as confirmed from SEM/EDS and XRD analyses discussed later), resulting in a denser microstructure. Additionally, the formation of cementitious binding phases consumes water and leads to swelling or expansion of gels. The presence of silica sand in the mortar mixes reduced shrinkage strains for mortars with reagent 1 and resulted in expansion for mixes with reagent 2 , compared to their paste counterparts at 56 days, as noted in Table 6 . This is because the voids in the mortar mixes were filled by silica sand particles making the matrix denser and more compact. It can also be attributed to the comparatively lower volume of pastes in the mortar mixes due to the addition of $30 \%$ silica sand.

The mortar mixes incorporating reagent 2 exhibited expansion (except mix CSM2N) in water immersion at all ages contrary to their paste compositions, and their corresponding mortar mixes with reagent 1 (Figure 10a,b). The predominant formation of cementitious reaction products and the compactness caused by silica sand grains lead to expansion for mixes with reagent 2 and lower shrinkage strains for CSM2N, compared to their paste counterparts. Furthermore, the formation of cementitious reaction products owing to a higher $\mathrm{Ca} / \mathrm{Si}$ ratio (varying from 0.73 to 1.02 ) of mortar mixes with reagent 2 than mixes with reagent $1(\mathrm{Ca} / \mathrm{Si}=0.59$ to 0.87$)$, consumes water for their reaction process, resulting in swelling/expansion and lower shrinkage strains, as shown in Figure 10a,b. Similar behaviour was reported in earlier investigations where a higher $\mathrm{Ca} / \mathrm{Si}$ ratio in FA/GGBFS based geopolymer composition led to the refinement of the microstructure and the capillary pores network [52].

The presence of low reactive FA-F in ternary compositions led to comparatively lower shrinkage/expansion strains (ranging from $-0.391 \%$ to $0.128 \%$ at 56 days) than their binary counterparts (ranging from $-0.576 \%$ to $0.348 \%$ at 56 days), as evident from Figure $10 a, b$, because the FA-F particles partially acted as filler. The combined effect of partially reacted FA-F particles and inert silica sand facilitated combating shrinkage strains by occupying the void spaces in ternary mortars, making the microstructure denser than the binary mortar mixes. It is consistent with the findings of a previous study where a larger proportion of fly ash in alkali-activated slag-fly ash-based mortars resulted in a lesser length change of the specimens [53] due to the dilution effect created by the fly ash acting as an inert filler.

The length and mass change of the mortar and paste (without silica sand) specimens at $56 / 90$ days in ambient/air storage curing regime have been tabulated in Table 7. The length change (shrinkage) for mortar specimens in the ambient/air curing regime ranged from $-0.032 \%$ to $-2.816 \%$ at 56 days, as presented in Figure 10a,b and Table 7 . Furthermore, for paste specimens, length change varied from $-0.084 \%$ to $-4.564 \%$ at 56 days. The incorporation of sand occupied the void spaces in the mortar matrix, densified the system's pore structure and resulted in comparatively lower shrinkage strains in mortar specimens. 


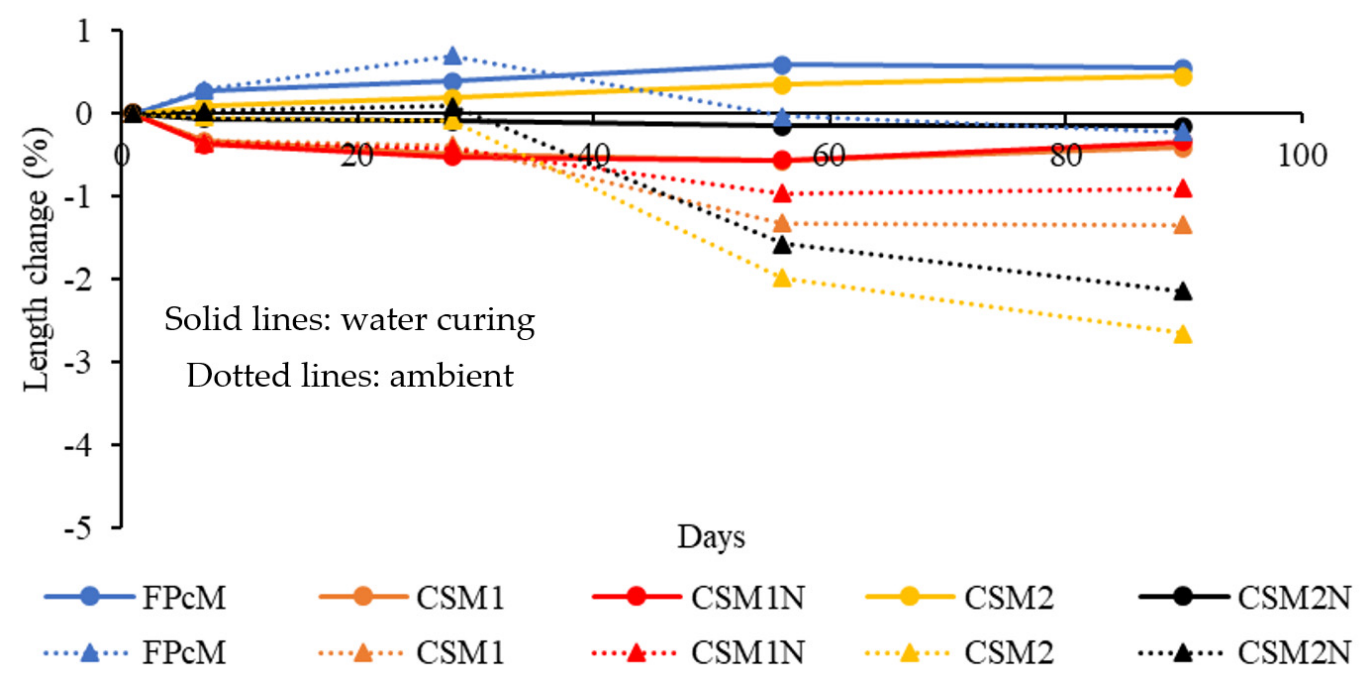

(a)

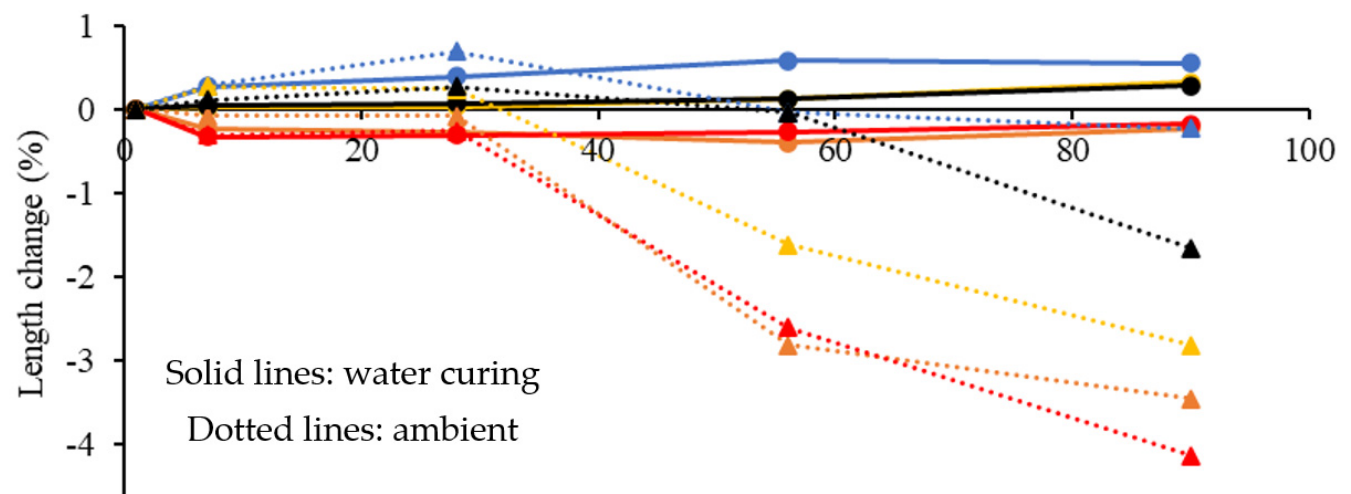

Days

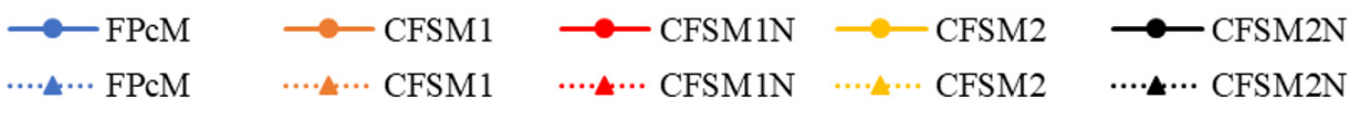

(b)

Figure 10. (a): Influence of the binary combination of SCMs in mortars on length change. (b): Influence of the ternary combination of SCMs in mortars on length change.

Table 7. Length and mass change of pastes and mortars in ambient curing regime.

\begin{tabular}{|c|c|c|c|c|c|c|c|c|c|}
\hline \multirow{2}{*}{ Paste } & \multicolumn{2}{|c|}{ Strain $(\%)$} & \multicolumn{2}{|c|}{ Mass Change (\%) } & \multirow{2}{*}{ Mortar } & \multicolumn{2}{|c|}{ Strain $(\%)$} & \multicolumn{2}{|c|}{ Mass Change (\%) } \\
\hline & 56-Day & 90-Day & 56-Day & 90-Day & & 56-Day & 90-Day & 56-Day & 90-Day \\
\hline $\mathrm{FP}_{\mathrm{C}}$ & -0.18 & -0.69 & -2.07 & -2.94 & $\mathrm{FP}_{\mathrm{C}} \mathrm{M}$ & -0.04 & -0.22 & -0.08 & -0.52 \\
\hline CS1 & -4.56 & -5.04 & -17.29 & -13.32 & CSM1 & -1.33 & -1.34 & -7.51 & -11.28 \\
\hline CS1N & -4.23 & -4.56 & -14.56 & -9.36 & CSM1N & -0.96 & -0.90 & -5.56 & -7.36 \\
\hline CS2 & -2.04 & -3.56 & -9.92 & -13.23 & CSM2 & -1.98 & -2.65 & -6.15 & -8.21 \\
\hline $\mathrm{CS} 2 \mathrm{~N}$ & -0.08 & -1.67 & 1.89 & -5.46 & CSM2N & -1.58 & -2.14 & -6.71 & -8.67 \\
\hline CFS1 & -3.64 & -5.24 & -10.12 & -13.76 & CFSM1 & -2.82 & -3.46 & -9.56 & -10.60 \\
\hline CFS1N & -3.24 & -4.91 & -7.37 & -9.38 & CFSM1N & -2.61 & -4.14 & -6.66 & -8.38 \\
\hline CFS2 & -2.00 & -3.59 & -6.67 & -10.85 & CFSM2 & -1.62 & -2.82 & -5.73 & -9.60 \\
\hline CFS2N & -2.17 & -3.30 & -5.50 & -7.14 & CFSM2N & -0.03 & -1.66 & -0.86 & -3.51 \\
\hline
\end{tabular}

Negative (-) sign in length and mass change indicates shrinkage and mass loss, and positive length and mass change denotes expansion and mass gain. 
The ternary mortar specimens with reagent 2 observed lower shrinkage strains (ranging from $-0.032 \%$ to $-1.616 \%$ ) at 56 days than their counterparts with reagent 1 (ranging from $-2.608 \%$ to $-2.816 \%$ ). This can be attributed to the densification of main alkali activation reaction products with the cementitious reaction products owing to the high calcium content in the reagent 2. A similar trend was noted for their paste counterparts, as noted in Table 7.

The shrinkage strains varied from $-0.96 \%$ to $-1.984 \%$ for binary mortars, whereas for ternary mortars, the shrinkage strains ranged between $-0.032 \%$ and $-2.816 \%$ at 56 days. The shrinkage strains in binary mortars became almost constant after 56 days and showed relatively minor variation in strains with age for different mix compositions than their ternary counterparts, as apparent from Figure 10a,b. This can be attributed to the significant crystalline (C-A-S-H/C-S-H) cementitious reaction products formation in binary mortars. In contrast, a combination of amorphous (N-C-A-S-H/N-A-S-H) and crystalline (C-A$\mathrm{S}-\mathrm{H}$ with traces of $\mathrm{C}-\mathrm{S}-\mathrm{H}$ ) reaction products were observed for ternary mortars. This lower variation in reaction products in binary mortars resulted in a lower variation of shrinkage/expansion strains compared to their ternary counterparts with age.

The mortar mixes exhibited lower variation in mass with age in water immersion (represented by solid lines) compared to those in the air curing regime (represented by dotted lines), as shown in Figure 11a,b. A slight decrease in mass was observed for mortars with reagent 1 in water immersion at seven days as with its binder compositions (in the authors' ongoing research), owing to the active formation of geopolymer/alkali activation products, resulting in the release of water.

The matrix composition 'CSM2' observed the highest mass gain of $1.86 \%$ at 56 days with respect to its mass at 1 day, as evident from Figure 11a,b and Table 6. The mortar compositions with reagent 2 exhibited higher mass change (varying from $0.64 \%$ to $1.86 \%$ at 56 days) at all ages owing to the higher calcium content in the system than their counterparts with reagent 1 (ranging from $0.22 \%$ to $0.99 \%$ at 56 days). The higher calcium content in binary mixes with reagent 2 resulted in the predominant formation of C-A-S-H gels with an additional C-S-H gel consuming water for the reaction process.

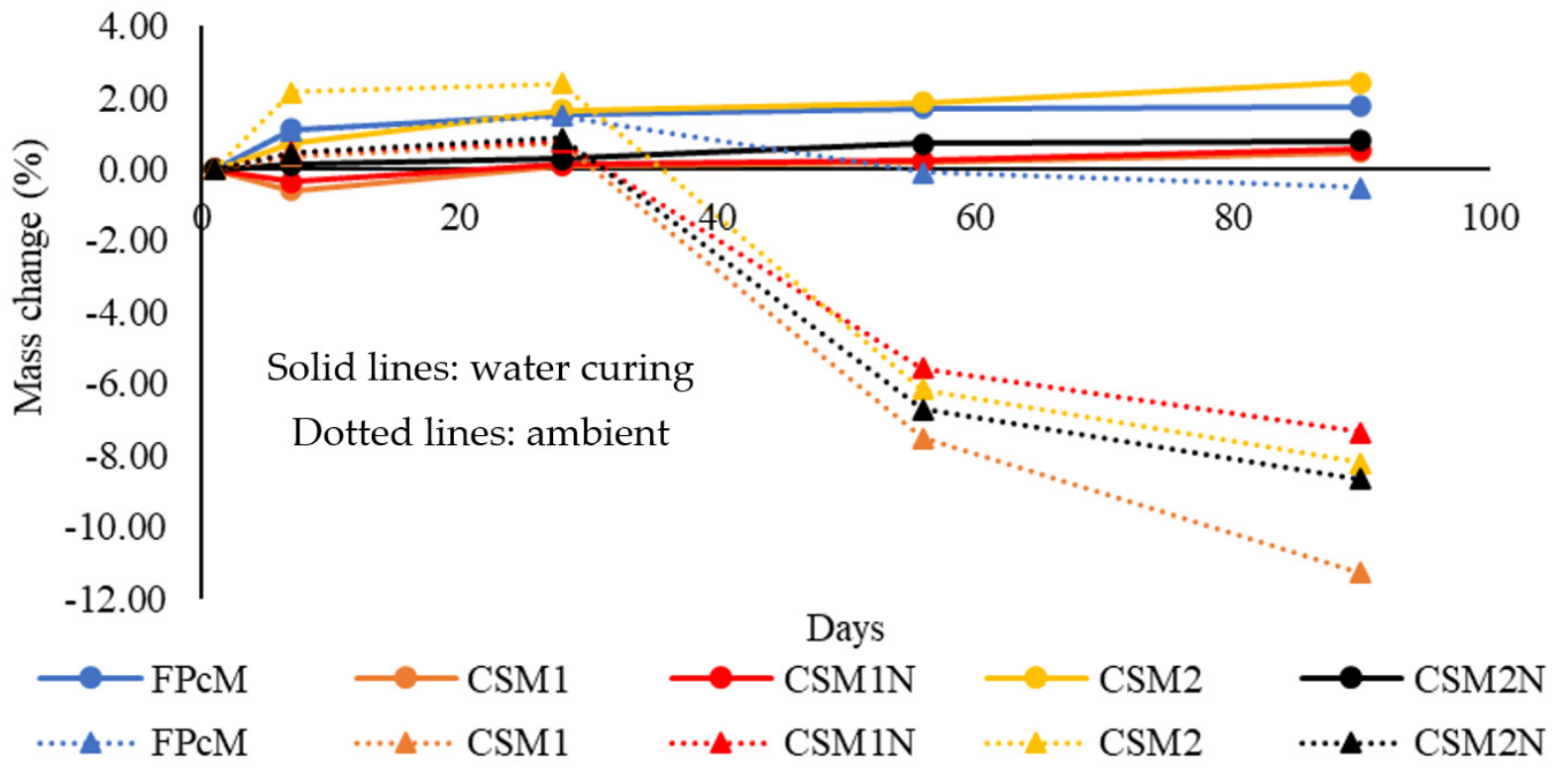

(a)

Figure 11. Cont. 


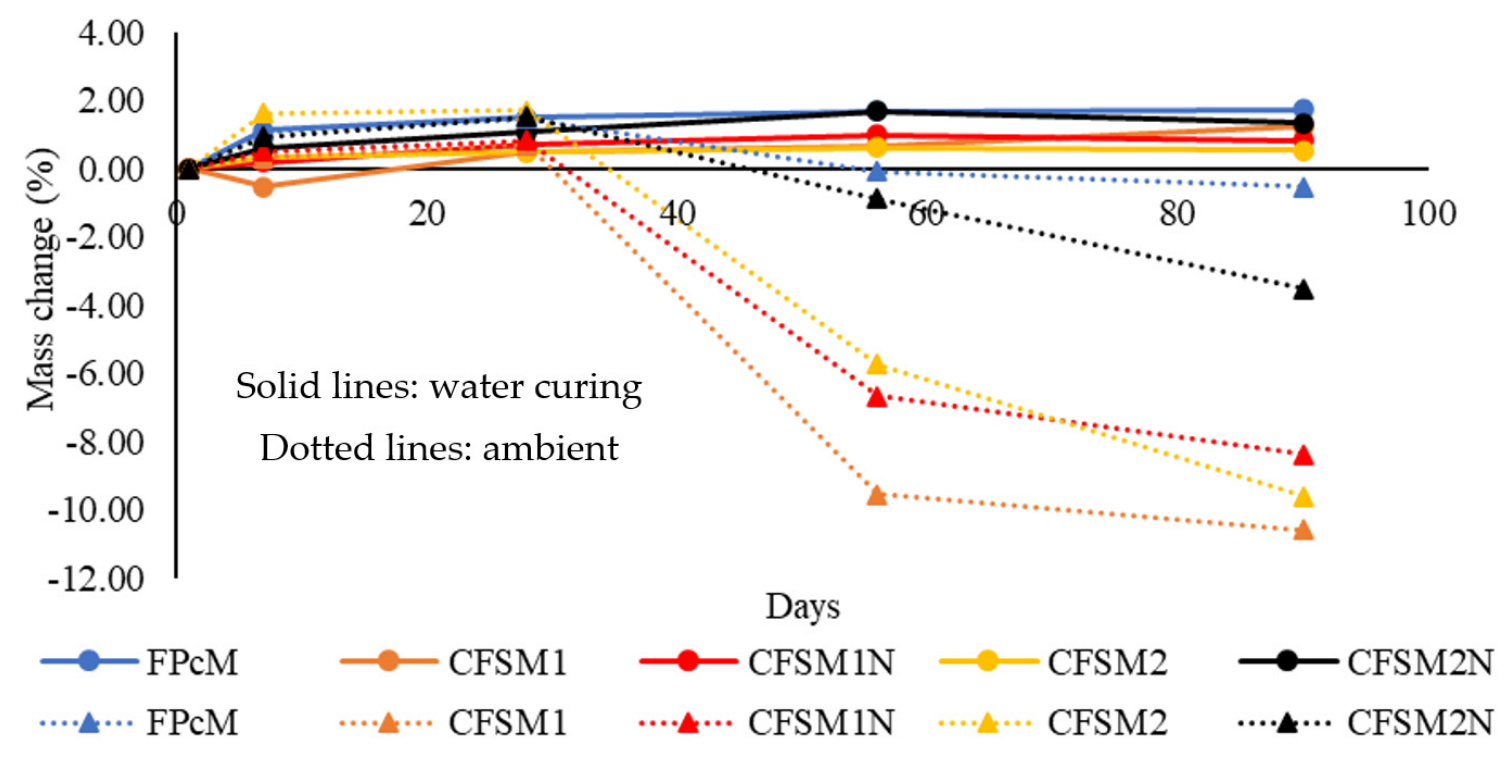

(b)

Figure 11. (a): Influence of the binary combination of SCMs in mortars on mass change. (b): Influence of the ternary combination of SCMs in mortars on mass change.

The mass decline with age for mortar specimens in the air curing regime is represented by dotted line graphs shown in Figure 11a,b. The mass change for mortar samples ranged from $-0.86 \%$ to $-9.56 \%$, and on the other hand, a mass change of up to $-17.21 \%$ was observed for the paste specimens at 56 days, as noted in Table 7 . This lower mass change for mortar specimens can be attributed to the densification caused by silica sand grains occupying the void spaces. The rate of mass change declined after 56 days for all the mix compositions in both water and air curing regimes, indicating the completion of reaction processes.

\subsubsection{Sorptivity}

The rate of water absorption for binary and ternary mortars is shown in Figure 12a,b. The root mean square values (linear correlation coefficients) of all the data were above 0.98 . The initial and secondary sorptivity indices are presented along with the freezethaw resistance characteristics of all the mortar compositions in Table 8. The binary mortar specimens observed initial sorptivity indices ranging from $2.0 \times 10^{-3} \mathrm{~mm} / \sqrt{ } \mathrm{s}$ to $5.1 \times 10^{-3} \mathrm{~mm} / \sqrt{ } \mathrm{s}$. On the other hand, the ternary mixes exhibited up to $52 \%$ lower initial sorptivity indices (varying from $1.0 \times 10^{-3} \mathrm{~mm} / \sqrt{ } \mathrm{s}$ to $3.3 \times 10^{-3} \mathrm{~mm} / \sqrt{ } \mathrm{s}$ ) than the binary mixes. This can be attributed to the lower geopolymerisation potential of fly ash class $\mathrm{F}$ incorporated in the ternary mixes. Therefore, some un-hydrated fly ash class F particles acted as fillers and occupied the mortar's void spaces. This reduced the number of connected voids, decreasing capillary rise and permeability for ternary mortar compositions.

Mortars incorporating reagent 2 demonstrated up to three times higher initial sorptivity indices than the mixes with reagent 1 , owing to the higher calcium content in the system. This higher calcium content led to the predominant formation of cementitious reaction products (C-A-S-H/C-S-H) consuming water for the reaction process. However, a combination of crystalline cementitious and amorphous geopolymer products (N-A-S$\mathrm{H} / \mathrm{N}-\mathrm{C}-\mathrm{A}-\mathrm{S}-\mathrm{H}$ ) was observed for mixes with reagent 1, resulting in the densification of the microstructure. Additionally, the amorphous geopolymer gels occupied the void spaces more effectively than the crystalline cementitious gels, which led to comparatively fewer voids in the system. The mixes (CSM1N, CSM2N, CFSM1N and CFSM2N) with an equal proportion of FA and GGBFS also exhibited higher initial sorptivity indices than the mixes (CSM1, CSM2, CFSM1 and CFSM2) with 5\% to 10\% lower GGBFS content, as presented in 
Table 8. All the AAM compositions exhibited lower or equal secondary sorptivity indices than that of the control mortar compositions.

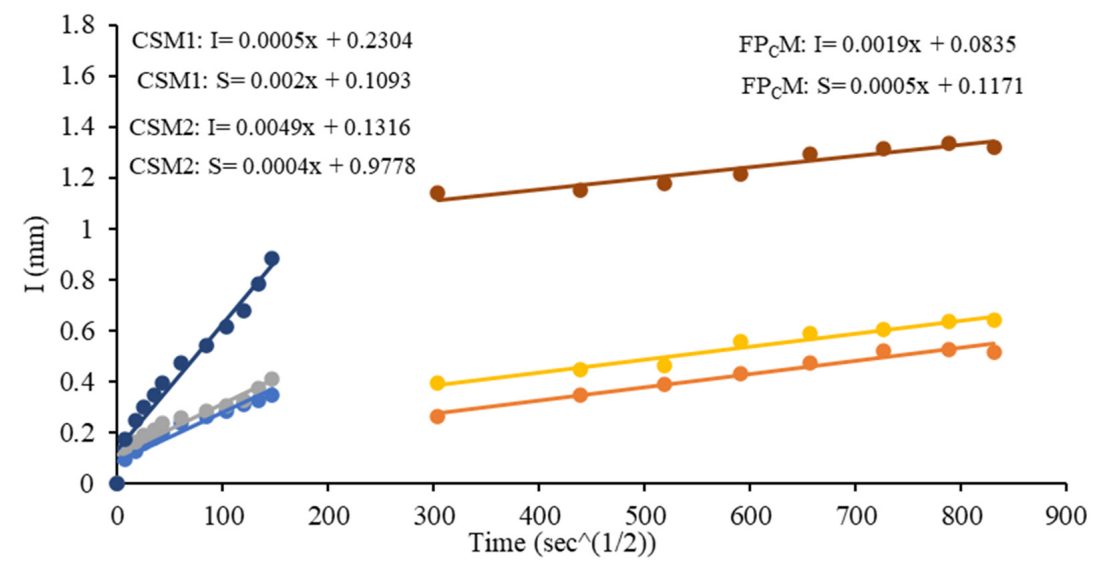

(a)

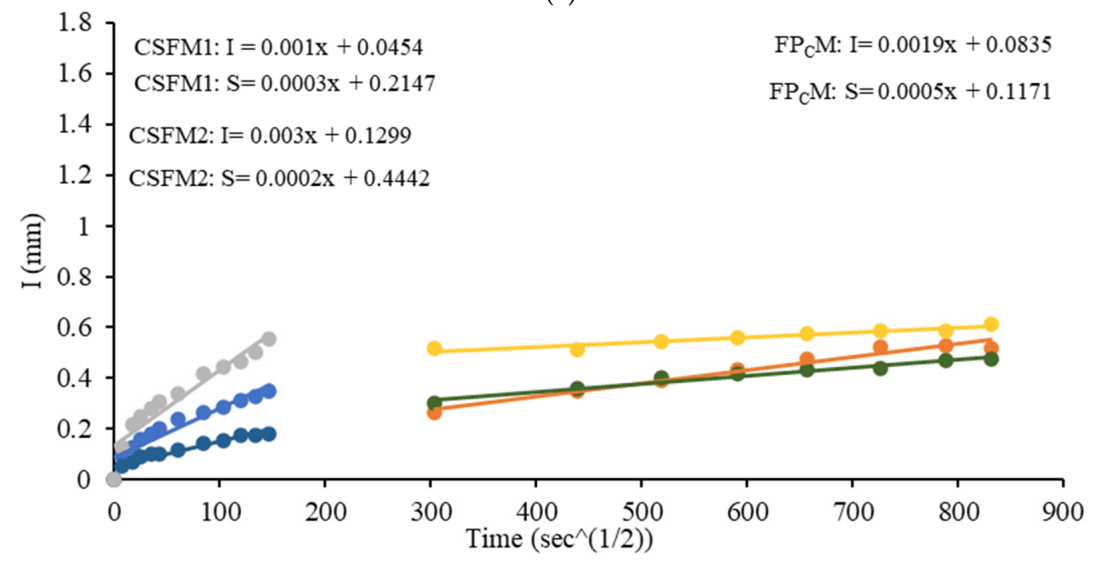

(b)

Figure 12. (a): Sorptivity indices for binary mortars. (b): Sorptivity indices for ternary mortars.

Table 8. Mechanical and durability characteristics of mortars.

\begin{tabular}{|c|c|c|c|c|c|c|c|c|c|c|c|}
\hline \multirow{2}{*}{$\begin{array}{c}\text { Mix } \\
\text { Designation }\end{array}$} & \multicolumn{3}{|c|}{$\begin{array}{l}\text { Ultrasonic Pulse Velocity } \\
\text { Longitudinal Direction }(355.6 \mathrm{~mm})\end{array}$} & \multicolumn{3}{|c|}{$\begin{array}{c}\text { Ultrasonic Pulse Velocity } \\
\text { Transverse Direction }(50.8 \mathrm{~mm})\end{array}$} & \multirow{2}{*}{$\begin{array}{c}\text { Initial } \\
\text { Sorptivity } \\
(\mathrm{mm} / \sqrt{ } \mathbf{s})\end{array}$} & \multirow{2}{*}{$\begin{array}{l}\text { Secondary } \\
\text { Sorptivity } \\
(\mathrm{mm} / \sqrt{ } \mathbf{s})\end{array}$} & \multirow{2}{*}{$\begin{array}{l}\text { Density } \\
\left(\mathrm{kg} / \mathrm{m}^{3}\right)\end{array}$} & \multicolumn{2}{|c|}{$\begin{array}{l}\text { Compressive } \\
\text { Strength (MPa) }\end{array}$} \\
\hline & $\begin{array}{c}0 \\
\text { Cycles } \\
\end{array}$ & $\begin{array}{c}30 \\
\text { Cycles }\end{array}$ & $\begin{array}{c}60 \\
\text { Cycles }\end{array}$ & $\begin{array}{c}0 \\
\text { Cycles }\end{array}$ & $\begin{array}{c}30 \\
\text { Cycles }\end{array}$ & $\begin{array}{c}60 \\
\text { Cycles }\end{array}$ & & & & 28-Day & 56-Day \\
\hline $\mathrm{FP}_{\mathrm{C}} \mathrm{M}$ & 4133 & 4123 & 4171 & 4080 & 3893 & 4080 & $1.9 \times 10^{-3}$ & $5 \times 10^{-4}$ & 1878 & 43.5 & 50 \\
\hline CSM1 & 3240 & 3231 & 3299 & 2372 & 1917 & 2670 & $2.0 \times 10^{-3}$ & $5 \times 10^{-4}$ & 2128 & 42.6 & 49 \\
\hline CSM1N & 3502 & 3237 & 3386 & 2713 & 2098 & 2713 & $2.3 \times 10^{-3}$ & $5 \times 10^{-4}$ & 2046 & 35 & 41.5 \\
\hline CSM2 & 3746 & 3543 & 3415 & 3777 & 3777 & 3777 & $4.9 \times 10^{-3}$ & $4 \times 10^{-4}$ & 2047 & 41.2 & 48.5 \\
\hline CSM2N & 4049 & 3908 & 3785 & 2452 & 2463 & 2463 & $5.1 \times 10^{-3}$ & $4 \times 10^{-4}$ & 2079 & 35.8 & 40 \\
\hline CFSM1 & 3320 & 3275 & 3352 & 2656 & 2656 & 2965 & $1.0 \times 10^{-3}$ & $3 \times 10^{-4}$ & 2034 & 40.4 & 45.2 \\
\hline CFSM1N & 3367 & 3336 & 3211 & 3517 & 3469 & 3290 & $1.1 \times 10^{-3}$ & $3 \times 10^{-4}$ & 1953 & 34 & 38.1 \\
\hline CFSM2 & 3205 & 3199 & 2987 & 2266 & 2297 & 2266 & $3.0 \times 10^{-3}$ & $2 \times 10^{-4}$ & 2031 & 42 & 46.4 \\
\hline CFSM2N & 3607 & 3589 & 3713 & 3617 & 3642 & 3642 & $3.3 \times 10^{-3}$ & $2 \times 10^{-4}$ & 1974 & 38.1 & 41.2 \\
\hline
\end{tabular}

\subsubsection{Freeze-Thaw Resistance of Mortars}

Table 8 presents the mechanical and durability characteristics of mortars. The mechanical properties have been described in terms of 28-day dry density and 28/56 days compressive strength. The durability of mortars has been characterized by initial/secondary sorptivity indices and ultra-sonic pulse velocity (UPV) in the longitudinal/transverse direction of the specimens at 0,30 and 60 cycles of freezing and thawing. The variation in mass and relative dynamic modulus in percentage have been noted in Figures 13 and 14. The AAM mixes exhibited UPVs varying from $3205 \mathrm{~m} / \mathrm{s}$ to $4049 \mathrm{~m} / \mathrm{s}$ in the longitudinal 
direction and from $2266 \mathrm{~m} / \mathrm{s}$ to $3777 \mathrm{~m} / \mathrm{s}$ in the transverse direction, respectively, at 0 cycles of freezing and thawing. A steep increase in mass up to $1.8 \%$ has been observed for the binary mortar mixes (CSM1, CSM1N, CSM2 and CSM2N) and control mix $\left(\mathrm{FP}_{\mathrm{C}} \mathrm{M}\right)$ at 30 freeze-thaw cycles as noted in Figure 13. A decrease of up to $23 \%$ and $5 \%$ was noted for UPV measurements in the transverse direction for the binary and control mortars at 30 freeze-thaw cycles, as noted in Table 8.

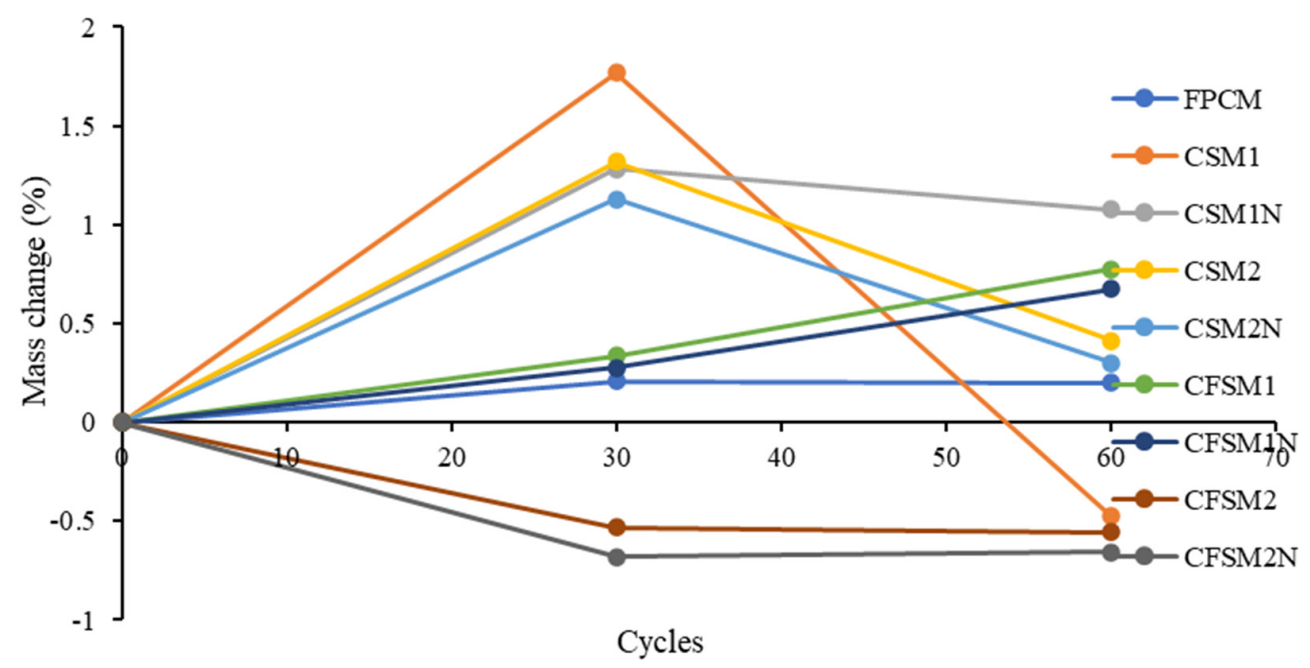

Figure 13. Mass change in percentage at 0,30 and 60 freeze-thaw cycles.

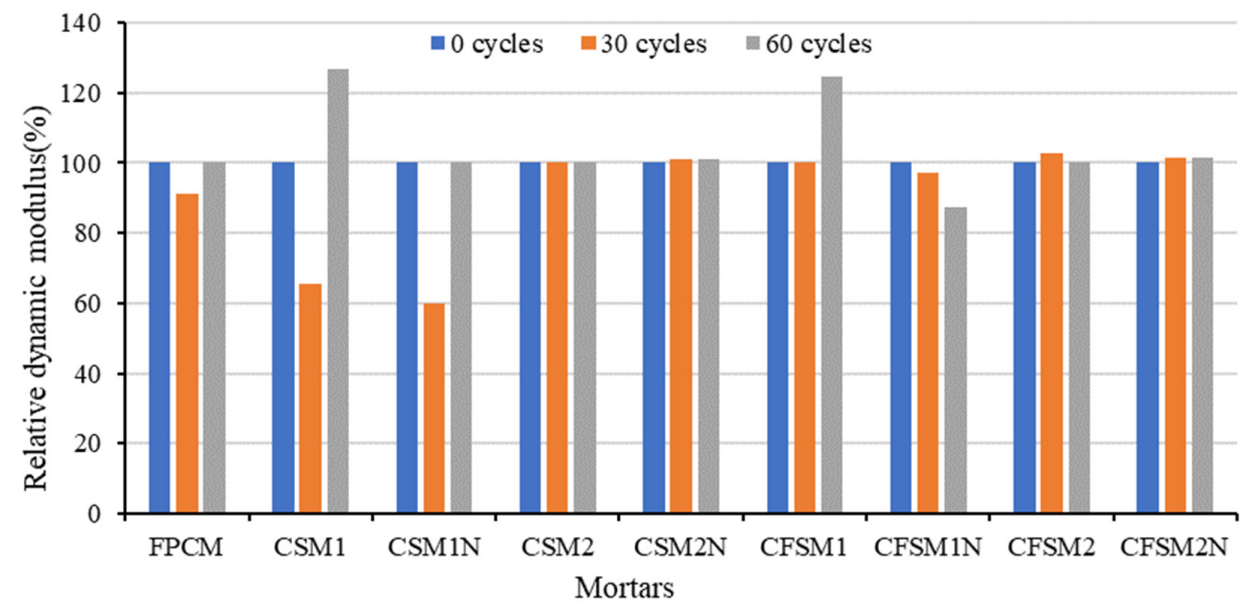

Figure 14. Relative dynamic modulus at 0,30 and 60 freeze-thaw cycles.

Correspondingly, decreases of up to $40 \%$ and $9 \%$ have been noted in the RDME of the binary and control mixes as indicated in Figure 14. This can be attributed to $54 \%$ to $100 \%$ higher primary and $66 \%$ to $100 \%$ higher secondary sorptivity indices of the binary mortars than their ternary counterparts. A reduction of up to $8 \%$ for UPV in the longitudinal direction was observed for binary mortars at 30 cycles of freezing and thawing. This reduction in UPV (longitudinal and transverse directions) and RDME values was more pronounced in mortars incorporating reagent 1 than their counterparts with reagent 2 . The dominant formation of cementitious reaction products (C-S-H/C-A-S-H) in mortars with reagent 2 (CSM2, CSM2N, CFSM2 and CFSM2N) made them more compact and less susceptible to damage because of freeze-thaw cycles. A similar observation was made in earlier investigations where the varying compactness of different mortar compositions was responsible for varying resistance to freeze-thaw damage [54]. All the mortar mixes reported $100 \%$ or more RDME values after 60 cycles, except mix CFSM1N (RDME $=87.5 \%$ ). These improvements in RDME, UPV (transverse direction), and corresponding reductions 
in mass change values (Figures 13 and 14) can be attributed to the probable re-arrangement of binding phases (crystalline C-S-H/C-A-S-H and amorphous N-A-S-H/N-C-A-S-H) due to accelerated freeze-thaw cycles, which densified the microstructure. These findings are supported by previous research on fly ash and slag-based mortars/concretes, where the refinement of the pore structure due to rapid freeze-thaw cycles resulted in significant recovery of the specimens $[25,54]$.

\subsection{Microstructural Analysis}

The morphology and microstructural characteristics of the mortar specimens were studied under a scanning electron microscope (SEM) at 28 days. The reaction products and the elemental compositions were determined using SEM/EDS and XRD analyses, as discussed in the following subsections to support the findings of mechanical and durability characteristics of mortars.

\subsubsection{SEM/EDS Analysis}

The morphology of the binary mortars appears to be denser with a smaller number of un-hydrated/partially hydrated fly ash particles than their ternary counterparts, as shown in Figure 15a-d. The fly ash particles are seen to be embedded in the matrix of ternary mortars CFSM1 and CFSM2, as indicated in Figure 15c,d. This can be attributed to the relatively lower reactivity of fly ash class $\mathrm{F}$ particles. The control mortar $\left(\mathrm{FP}_{\mathrm{C}} \mathrm{M}\right)$ exhibited the highest compressive strength. It appeared to be the most compact among all the mortar specimens, with some of the FA-F particles acting as inert material filling up the void spaces, as noted in Figure 15e.

The main reaction product for binary mortar CSM1 consisted of C-A-S-H and calciumrich N-C-A-S-H binding phases as indicated in SEM/EDS graphs presented in Figure 16a. The traces of $\mathrm{MgO}$ can also be identified from the EDS and XRD analyses. The presence of the above-mentioned compounds can be confirmed from the elements $(\mathrm{Ca}=13.5 \%$, $\mathrm{Si}=10.7 \%, \mathrm{Al}=5.6 \%, \mathrm{Mg}=5.2 \%, \mathrm{Na}=2.8 \%$ and $\mathrm{O}=49.6 \%$ ) noted in the EDS graph. The partially hydrated round fly ash class $\mathrm{C}$ and angular GGBFS particles can be observed in the SEM micrograph.

The dominant reaction product for binary mortar CSM2 mortar consisted of C-A-S-H, as shown by the elements $(\mathrm{Ca}=17.9 \%, \mathrm{Si}=7.7 \%, \mathrm{Al}=4.1 \%$ ) with higher percentages in the EDS analysis presented in Figure 16b. An additional binding phase composed of C-S-H can be observed in the SEM micrograph because of the higher calcium content in the system than the mortar CSM1. The higher calcium content is attributed to the higher calcium content in reagent $2\left(\mathrm{Ca}(\mathrm{OH})_{2}: \mathrm{Na}_{2} \mathrm{SO}_{4}=2.5: 1\right)$ compared to reagent $1\left(\mathrm{Ca}(\mathrm{OH})_{2}\right.$ : $\left.\mathrm{Na}_{2} \mathrm{SiO}_{3} \cdot 5 \mathrm{H}_{2} \mathrm{O}=1: 2 \cdot 5\right)$.

The characteristic round-shaped partially hydrated fly ash class F (FA-F) particles can be seen well embedded in the matrix of CFSM1 mortar shown in the SEM image (Figure 16c). The main reaction product consisted of $\mathrm{Si}-\mathrm{Al}$ rich $\mathrm{C}-\mathrm{A}-\mathrm{S}-\mathrm{H}$ gel, as evident from the elements $(\mathrm{Ca}=12 \%, \mathrm{Si}=6.2 \%, \mathrm{Al}=3.7 \%$ and $\mathrm{O}=51.9 \%)$ in the EDS analysis.

A mix of amorphous and crystalline products can be observed from the SEM micrograph of CFSM2 presented in Figure 16d. Cracks are visible in the micrograph as the samples were prepared from the core of the specimens tested under compression. The main reaction product consisted of C-A-S-H gel with traces of C-S-H as determined from major elements ( $\mathrm{Ca}=17.5 \%, \mathrm{Si}=14.3 \%, \mathrm{Al}=10.4 \%$ and $\mathrm{O}=36.3 \%)$ in the EDS analysis. A lesser number of partially hydrated fly ash particles can be seen in the SEM image (Figure 16d) of CFSM2 than the ternary (CFSM1) mortar with reagent-1 (Figure 16c).

In general, mortar mixes with reagent 2 exhibited a denser microstructure, as evident from the formation of C-A-S-H with additional C-S-H gels than their counterparts with reagent 1 due to higher calcium content in the mix compositions. This resulted in enhanced mechanical and durability characteristics in terms of higher compressive strength, lower shrinkage/expansion, and better resistance to freeze-thaw cycles of mortar mixes with reagent 2 , compared to their counterparts with reagent 1. 


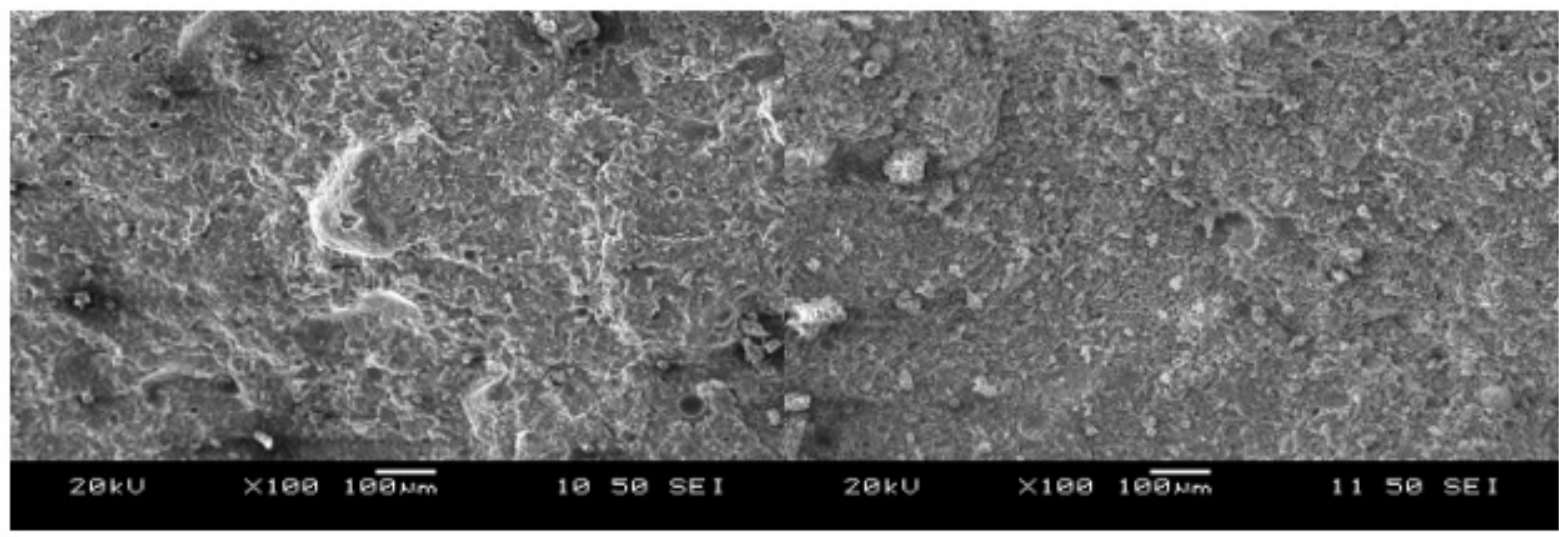

(a)

(b)

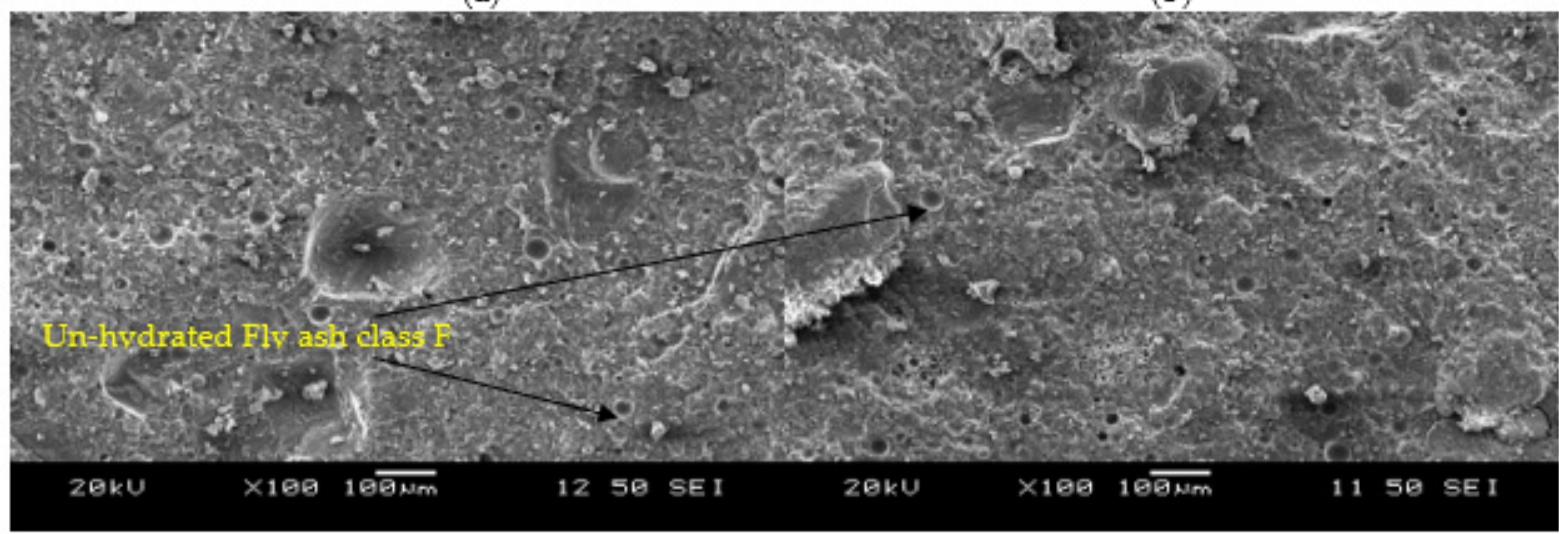

(c)

(d)

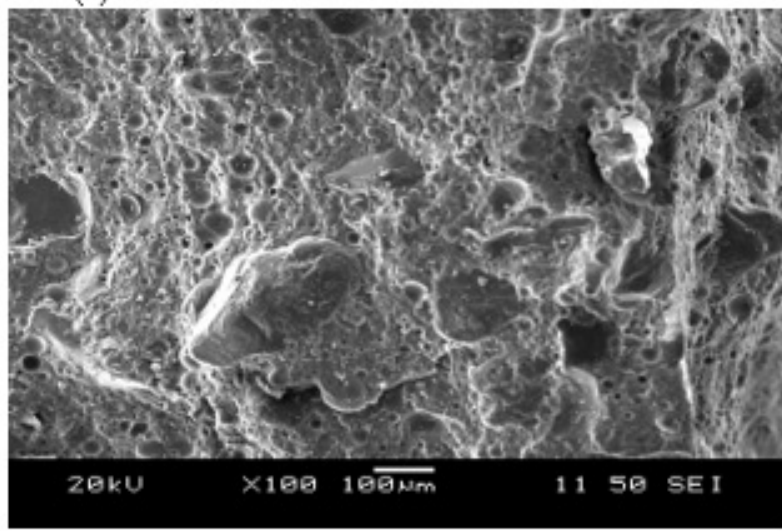

(e)

Figure 15. Morphology of the mortars (a) CSM1, (b) CSM2, (c) CFSM1, (d) CFSM2, (e) FP ${ }_{C} M$.

Partially hydrated cement and fly ash class F particles can be seen as part of the control mortar matrix $\left(\mathrm{FP}_{\mathrm{C}} \mathrm{M}\right)$ presented in Figure 16e. The dominant hydration product $\mathrm{C}-\mathrm{S}-\mathrm{H}$ gel determined from the ruling elements $(\mathrm{Ca}=24.6 \%, \mathrm{Si}=9.9 \%, \mathrm{Al}=3.9 \%$ and $\mathrm{O}=45.8 \%$ ) in SEM/EDS analysis is responsible for the highest compressive strength among all the mortars. 

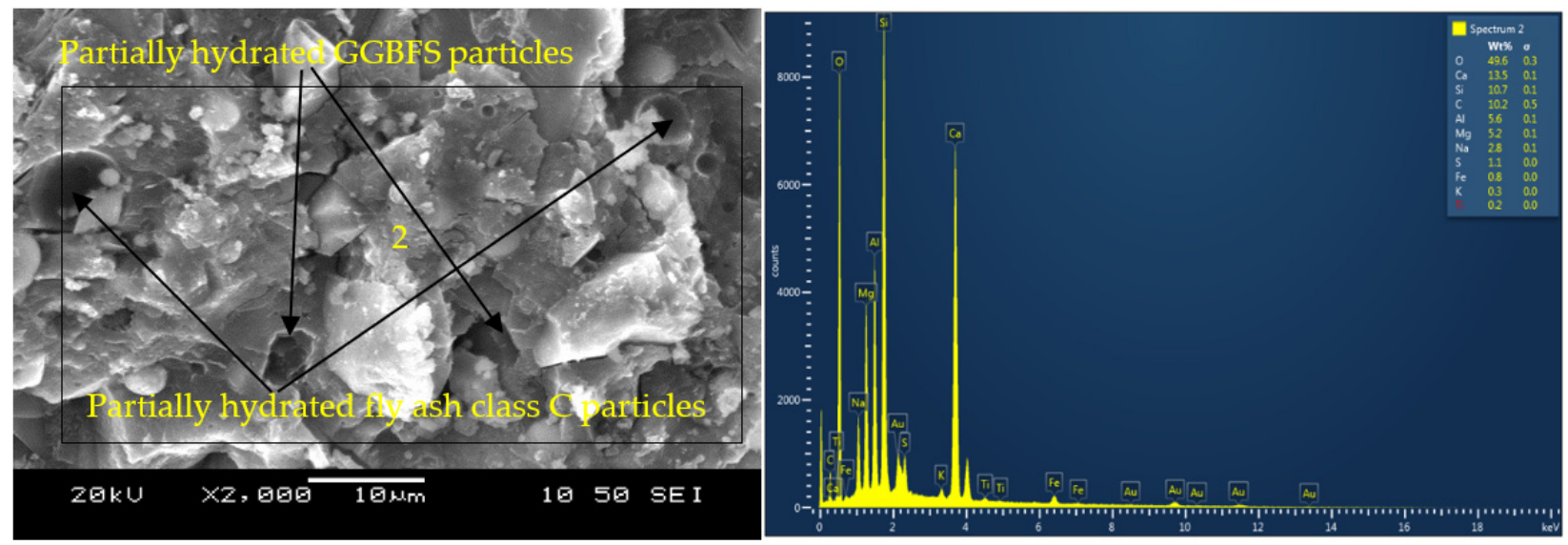

(a)
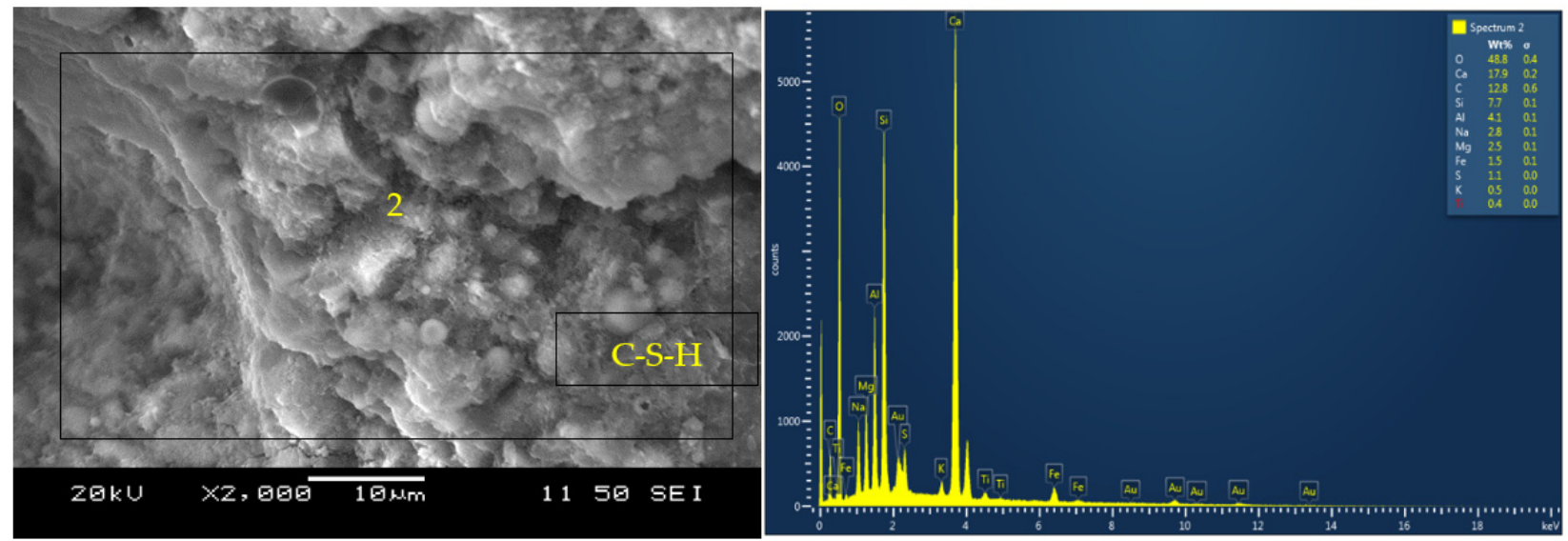

(b)
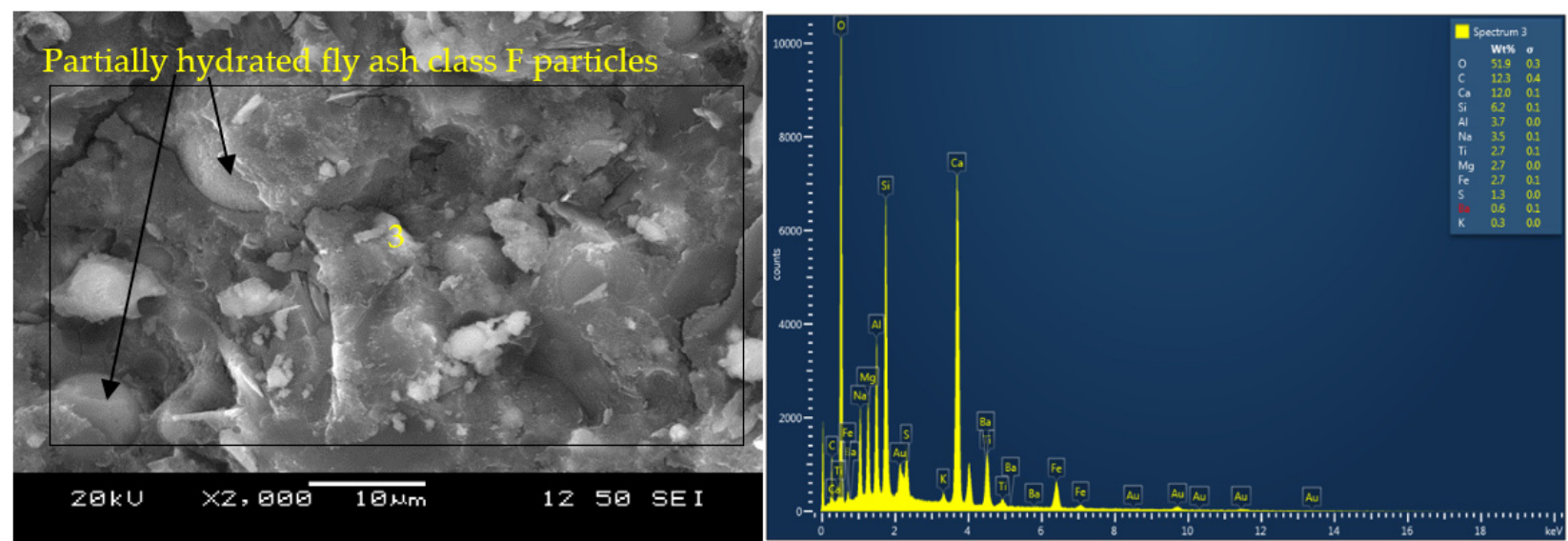

(c)

Figure 16. Cont. 

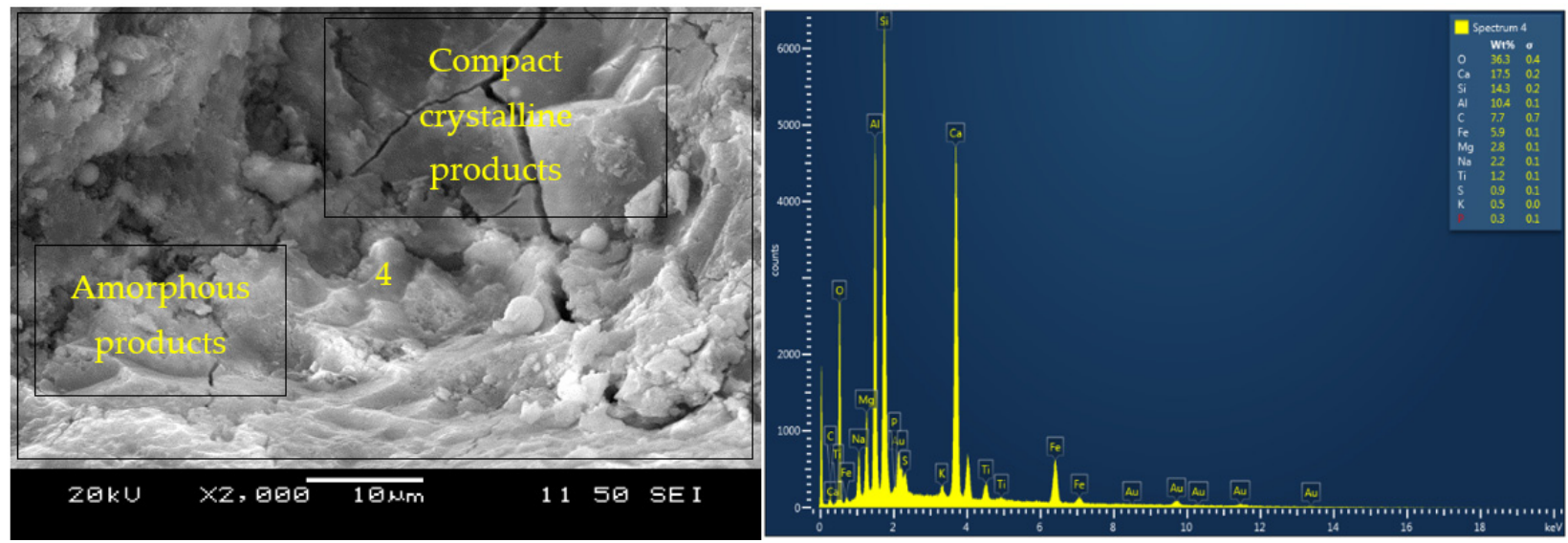

(d)
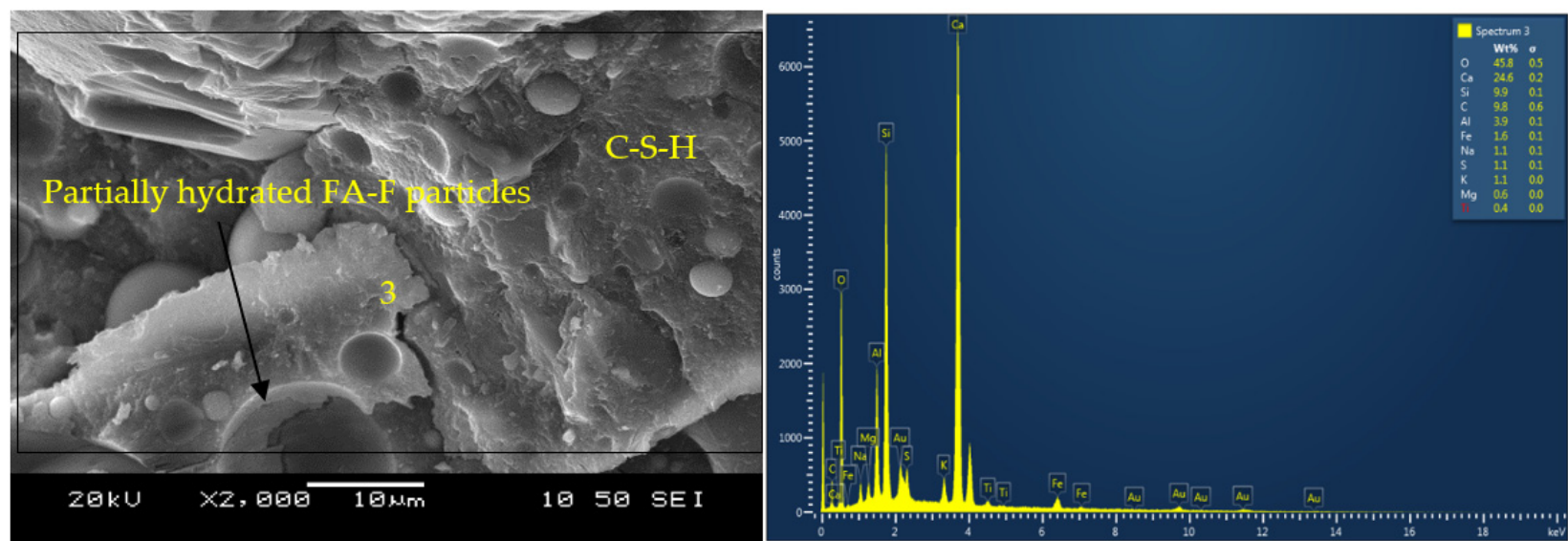

(e)

Figure 16. SEM micrographs and EDS analysis of the mortars (a) CSM1, (b) CSM2, (c) CFSM1, (d) CFSM2, (e) FP $\mathrm{CM}$.

\subsubsection{XRD Analysis}

The XRD diffraction patterns of the binary/ternary mortar mix incorporating reagents 1 and 2 are illustrated in Figure 17a,b. A mix of peaks and broad humps can be identified in the diffractograms for binary and ternary mortars, signifying a combination of reaction products composed of crystalline and amorphous phases. For instance, the peak at $36.7^{\circ} 2 \theta$ for all the mortar compositions consisted of multiple minerals (quartz, wadalite, gehlenite, hydrotalcite and gypsum). The dominant crystalline phases of quartz were seen for all the mix compositions, with its highest peak at about $26.7^{\circ} 2 \theta$. The sharpest and highest intensity peak for the quartz phase was observed in the CFSM2 diffractogram (indicating dominant crystalline binding phase) with a greater number of peaks than their counterparts (CFSM1) and other binary (CSM1) mixes with reagent 1 . Portlandite (calcium hydroxide) can also be seen around $34.2^{\circ} 2 \theta$ in ternary mix CFSM2 diffractogram because of the reagent 2 composition and is responsible for forming additional binding phases. This peak characterization is consistent with the previous investigations on fly ash/slag binders [55]. The main binding phases consisted of C-A-S-H and calcium-rich N-C-A-S-H for the binary mortars. In ternary mortars, N-A-S-H and N-C-A-S-H were observed for mixes with reagent 1 , and a blend of C-A-S-H and N-C-A-S-H was identified with traces of C-S-H for mixes with reagent 2 . The presence of these binding phases in the XRD analysis validated the SEM/EDS analysis of binary and ternary mortars. The small reflections of ettringite were seen for ternary mortar CFSM2 with its maximum peak at $15.5^{\circ} 2 \theta$ as presented in Figure 17b; however, no expansion cracks were observed in the specimens. The traces of gypsum and periclase $(\mathrm{MgO})$ were also determined in all the compositions. The presence 
of gypsum prevented the flash setting of these mixes. The $\mathrm{MgO}$ content in the mortars is known to reduce shrinkage and facilitate the self-healing behaviour of cementitious composites by its inherent expansive characteristics $[33,34]$.
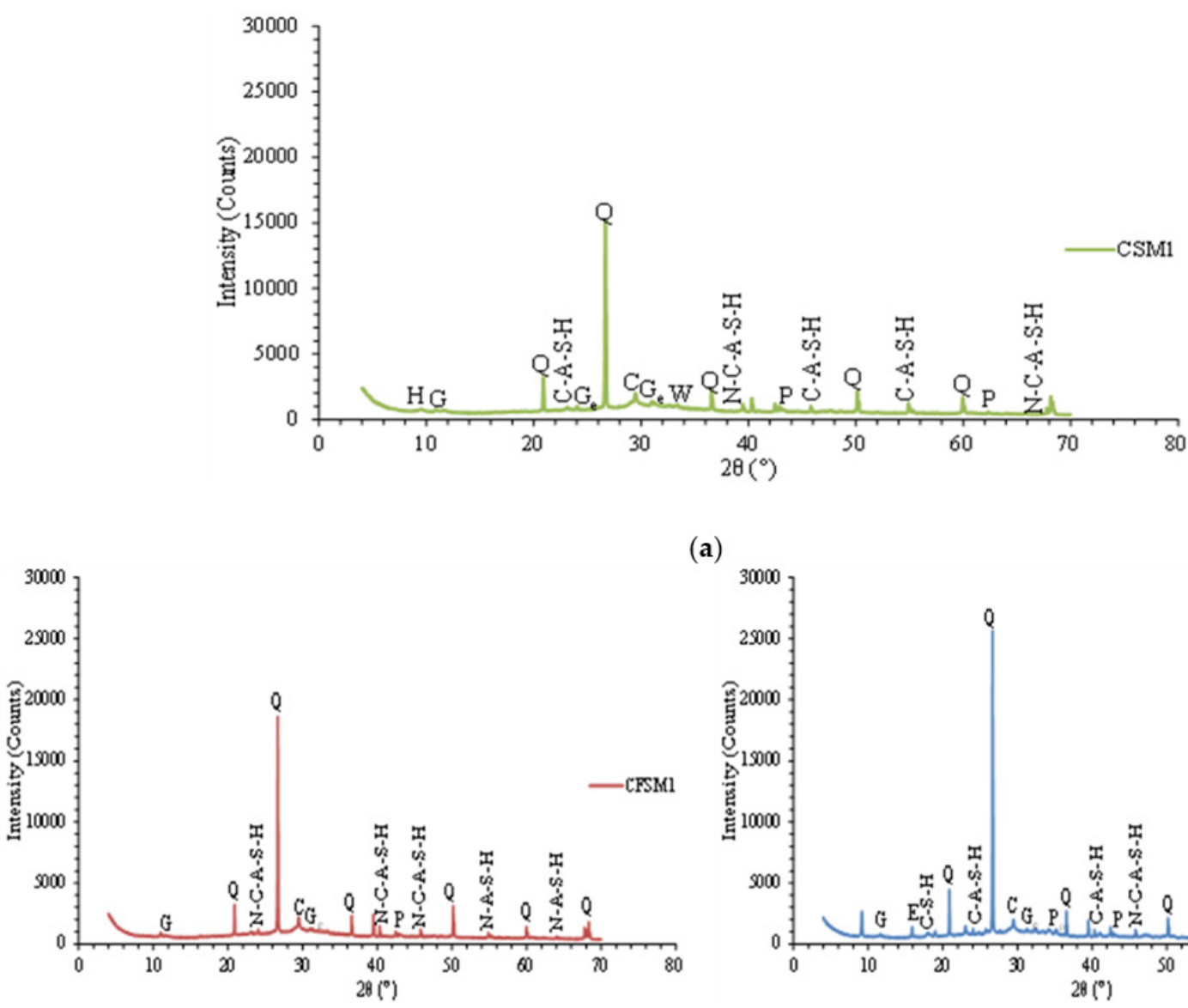

(a)

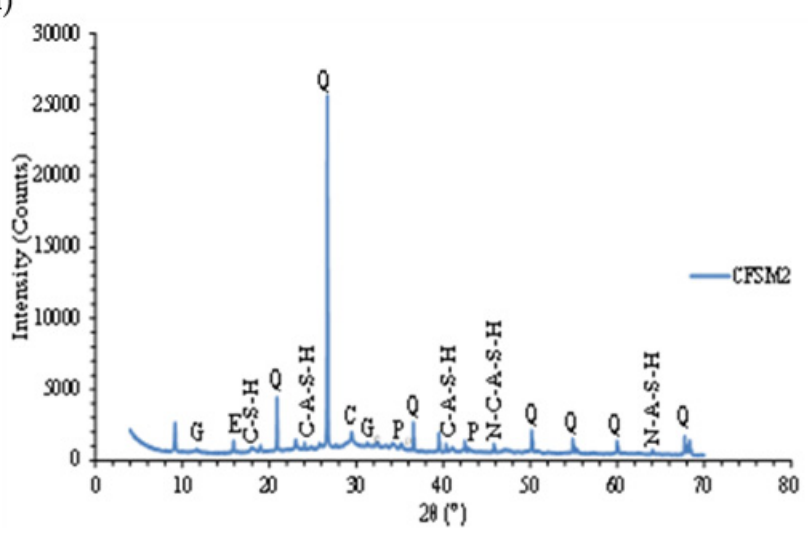

(b)

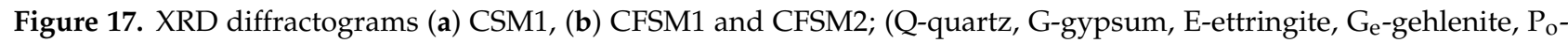
portlandite, P-periclase, $\mathrm{H}$-hydrotalcite, $\mathrm{C}$-calcite, $\mathrm{W}$-wadalite).

\section{Conclusions}

The performance evaluation of mortars developed from binary (fly ash class $C$ 'FA- $C$ ' + ground granulated blast furnace slag 'GGBFS') and ternary (fly ash class $C$ 'FA-C' + fly ash class F 'FA-F' + ground granulated blast furnace slag 'GGBFS') proportions/combination of precursors with two types of powder-based reagent combination and a constant amount of silica sand has been presented. The reagent 1 was composed of calcium hydroxide and sodium metasilicate (calcium hydroxide: sodium metasilicate $=1: 2.5$ ), while reagent 2 consisted of calcium hydroxide and sodium sulphate (calcium hydroxide: sodium sulphate $=2.5: 1$ ). The main conclusions drawn from the mechanical, durability, and microstructural analyses of the developed mortar compositions are as follows:

1. The 28-day compressive strength of mortars ranged between $34 \mathrm{MPa}$ and $44 \mathrm{MPa}$. The mortars incorporating reagent 2 (CSM2, CSM2N, CFSM2 and CFSM2N) exhibited higher compressive strengths than their counterparts with reagent 1 (CSM1, CSM1N, CFSM1 and CFSM1N). This can be attributed to the dominant formation of portlandite $\left(\mathrm{CaOH}_{2}\right)$ in the reagent 2 mixes, which is responsible for synthesizing additional binding phases (C-S-H), resulting in the denser and more compact microstructure. SEM/EDS and XRD analysis, also revealed the formation of C-A-S-H/N-C-A-S-H 
and C-A-S-H/C-S-H as the primary binding phases for mortars with reagent 1 and reagent 2 , respectively.

2. Ternary mortars (represented by CFS) demonstrated up to 1.7 times higher fracture toughness and 3.6 times higher crack tip toughness than their binary (represented by CS) counterparts, irrespective of reagent types, owing to the formation of a combination of binding phases (N-A-S-H/N-C-A-S-H and C-A-S-H). However, the mix CFSM1N (with an equal proportion of fly ash and GGBFS) exhibited lower fracture and crack tip toughness than its binary counterpart (CSM1N) due to its lowest peak load (in fracture energy test) and compressive strength. Generally, all the mortar mixes exhibited low level of fracture and crack tip toughness, which is ideal for using them in producing fibre-reinforced strain hardening composites.

3. Ternary mortars incorporating class $\mathrm{F}$ fly ash showed comparatively lower shrinkage/expansion (from $-0.391 \%$ to $0.128 \%$ ) than their binary (from $-0.576 \%$ to $0.348 \%$ ) and paste (from $-0.048 \%$ to $-0.436 \%$ ) counterparts at 56 days under water immersion. The incorporation of inert fine silica sand and low reactive FA-F reduced the shrinkage/expansion in water and air/ambient curing regimes by producing denser microstructure through filling the voids. Such densification of microstructure due to the addition of silica sand also produced a lower mass change of all mortar specimens (from $-0.86 \%$ to $-9.56 \%$ ) compared to their paste counterparts (mass change up to $-17.21 \%$ ) in the air curing regime at 56 days. Ternary mortars also exhibited up to $52 \%$ lower initial sorptivity (from $1.0 \times 10^{-3} \mathrm{~mm} / \sqrt{ } \mathrm{s}$ to $3.3 \times 10^{-3} \mathrm{~mm} / \sqrt{ } \mathrm{s}$ ) than their binary counterparts (from $2.0 \times 10^{-3} \mathrm{~mm} / \sqrt{ } \mathrm{s}$ to $5.1 \times 10^{-3} \mathrm{~mm} / \sqrt{ } \mathrm{s}$ ). The shrinkage and expansion characteristics of mortars was found to be influenced by the type of reagent, chemical ratios and curing regimes. In general, mortars with reagent 2 and reagent 1 demonstrated expansion and shrinkage, respectively, at all ages under the water curing regime.

4. The reagent 2 mortars exhibited better freeze-thaw resistance by showing no reduction in UPV and RDME (maintaining at 100\%) during 60 cycles of freeze-thaw due to their denser microstructure consisting mainly of crystalline C-A-S-H/C-S-H gels. Reagent 1 mortars exhibited $23 \%$ and $40 \%$ reduction of UPV and RDME, respectively, at 30 cycles, but subsequently showed comparable performance to their reagent 2 counterparts by achieving RDME of $100 \%$ at 60 cycles, possibly due to the re-arrangement of crystalline and amorphous gels at micro-level.

5. This research demonstrated the viability of producing ambient cured powder-based AAMs as green and sustainable alternatives to conventional cement-based mortars, having satisfactory mechanical, durability and microstructural characteristics. The developed AAMs have the potential to be used for structural applications and to produce high-performance fibre-reinforced strain hardening composites for resilient infrastructures.

Author Contributions: Conceptualization, D.S. and K.M.A.H.; methodology, D.S. and K.M.A.H.; formal analysis, D.S. and K.M.A.H.; investigation, D.S and K.M.A.H.; resources, K.M.A.H.; writingoriginal draft preparation, D.S. and K.M.A.H.; writing—review and editing, D.S. and K.M.A.H.; supervision, K.M.A.H.; project administration, K.M.A.H.; funding acquisition, K.M.A.H. All authors have read and agreed to the published version of the manuscript.

Funding: This research was funded by Natural Science and Engineering Research Council (NSERC), Canada, grant number RGPIN 5613-2019 and The APC was waived by MDPI.

Acknowledgments: The authors gratefully acknowledge the supports provided by the technical staffs of Concrete and Structure laboratories of the Department of Civil Engineering, Ryerson University, Toronto, Canada.

Conflicts of Interest: The authors declare no conflict of interest. 


\section{References}

1. Duxson, P.; Fernández-Jiménez, A.; Provis, J.L.; Lukey, G.C.; Palomo, A.; van Deventer, J.S. Van Deventer Geopolymer technology: The current state of the art. J. Mater. Sci. 2006, 42, 2917-2933. [CrossRef]

2. Provis, J.L. Alkali-activated materials. Cem. Concr. Res. 2018, 114, 40-48. [CrossRef]

3. Hossain, K.M.A. Properties of volcanic pumice based cement and lightweight concrete. Cem. Concr. Res. 2004, 34, $283-291$. [CrossRef]

4. Hassan, A.A.; Lachemi, M.; Hossain, K.M. Effect of metakaolin and silica fume on the durability of self-consolidating concrete. Cem. Concr. Compos. 2012, 34, 801-807. [CrossRef]

5. Kurda, R.; Silva, R.V.; de Brito, J. Incorporation of alkali-activated municipal solid waste incinerator bot-tom ash in mortar and concrete: A critical review. Materials 2020, 13, 3428. [CrossRef] [PubMed]

6. Huseien, G.F.; Sam, A.R.M.; Shah, K.W.; Asaad, M.A.; Tahir, M.M.; Mirza, J. Properties of ceramic tile waste based alkali-activated mortars incorporating GBFS and fly ash. Constr. Build. Mater. 2019, 214, 355-368. [CrossRef]

7. Candamano, S.; Crea, F.; Iorfida, A. Mechanical characterization of basalt fabric-reinforced alkali-activated matrix composite: A preliminary investigation. Appl. Sci. 2020, 10, 2865. [CrossRef]

8. Nematollahi, B.; Sanjayan, J.; Shaikh, F.U.A. Matrix design of strain hardening fiber reinforced engineered geopolymer composite. Compos. Part B Eng. 2016, 89, 253-265. [CrossRef]

9. Li, V.C.; Mishra, D.K.; Wu, H.C. Matrix design for pseudo-strain-hardening fibre reinforced cementitious composites. Mater. Struct. 1995, 28, 586-595. [CrossRef]

10. Li, V.C.; Wang, S.; Wu, C. Tensile strain-hardening behaviour of Polyvinyl Alcohol Engineered Cementitious Composites (PVA-ECC. ACI Mater. J. 2001, 98, 483-492.

11. Ding, Y.; Shi, C.-J.; Li, N. Fracture properties of slag/fly ash-based geopolymer concrete cured in ambient temperature. Constr. Build. Mater. 2018, 190, 787-795. [CrossRef]

12. Zhang, S.; Li, Z.; Ghiassi, B.; Yin, S.; Ye, G. Fracture properties and microstructure formation of hardened alkali-activated slag/fly ash pastes. Cem. Concr. Res. 2021, 144, 106447. [CrossRef]

13. Pan, Z.; Sanjayan, J.; Rangan, B.V. Fracture properties of geopolymer paste and concrete. Mag. Concr. Res. 2011, 63, 763-771. [CrossRef]

14. Trindade, A.C.C.; Curosu, I.; Liebscher, M.; Mechtcherine, V.; de Andrade Silva, F. On the mechanical performance of K- and Na-based strain-hardening geopolymer composites (SHGC) reinforced with PVA fibers. Constr. Build. Mater. 2020, 248, 01-16.

15. Nematollahi, B.; Sanjayan, J.; Qiu, J.; Yang, E.-H. Micromechanics-based investigation of a sustainable ambient temperature cured one-part strain hardening geopolymer composite. Constr. Build. Mater. 2017, 131, 552-563. [CrossRef]

16. Li, Z.; Liu, J.; Ye, G. Drying shrinkage of alkali-activated slag and fly ash concrete; A comparative study with ordinary Portland cement concrete. Heron 2019, 64, 01-15.

17. Wang, G.; Ma, Y. Drying shrinkage of alkali-activated fly ash/slag blended system. J. Sustain. Cem. Mater. 2018, 7, 1-11. [CrossRef]

18. Abdel-Gawwad, H.A.; Abd El-Aleem, S. Effect of reactive magnesium oxide on properties of alkali activated slag geopolymer cement pastes. Ceram. Silikaty 2015, 59, 37-47.

19. Coppola, L.; Coffetti, D.; Crotti, E.; Candamano, S.; Crea, F.; Gazzaniga, G.; Pastore, T. The combined use of admixtures for shrinkage reduction in one-part alkali activated slag-based mortars and pastes. Constr. Build. Mater. 2020, 248, 118682. [CrossRef]

20. Adesanya, E.; Ohenoja, K.; Luukkonen, T.; Kinnunen, P.; Illikainen, M. One-part geopolymer cement from slag and pretreated paper sludge. J. Clean. Prod. 2018, 185, 168-175. [CrossRef]

21. Huseien, G.F.; Tahir, M.M.; Mirza, J.; Ismail, M.; Shah, K.W.; Asaad, M.A. Effects of POFA replaced with FA on durability properties of GBFS included alkali activated mortars. Constr. Build. Mater. 2018, 175, 174-186. [CrossRef]

22. Castel, A.; Foster, S.J.; Ng, T.; Sanjayan, J.G.; Gilbert, R.I. Creep and drying shrinkage of a blended slag and low calcium fly ash geopolymer Concrete. Mater. Struct. 2015, 49, 1619-1628. [CrossRef]

23. Alnkaa, A.; Yaprak, H.; Memiş, S.; Kaplan, G. Effect of Different Cure Conditions on the Shrinkage of Geopolymer Mortar Effect of Different Cure Conditions on the Shrinkage of Geopolymer Mortar. Int. J. Eng. Res. Dev. 2018, 14, 51-55.

24. Thomas, R.; Lezama, D.; Peethamparan, S. On drying shrinkage in alkali-activated concrete: Improving dimensional stability by aging or heat-curing. Cem. Concr. Res. 2017, 91, 13-23. [CrossRef]

25. Coppola, L.; Coffetti, D.; Crotti, E.; Gazzaniga, G.; Pastore, T. The Durability of One-Part Alkali-Activated Slag-Based Mortars in Different Environments. Sustainability 2020, 12, 3561. [CrossRef]

26. Wardhono, A.; Gunasekara, C.; Law, D.; Setunge, S. Comparison of long term performance between alkali activated slag and fly ash geopolymer concretes. Constr. Build. Mater. 2017, 143, 272-279. [CrossRef]

27. Adesina, A.; Das, S. Drying shrinkage and permeability properties of fibre reinforced alkali-activated composites. Constr. Build. Mater. 2020, 251, 119076. [CrossRef]

28. Yap, S.P.; Alengaram, U.J.; Jumaat, M.Z. Enhancement of mechanical properties in polypropylene- and nylon-fibre reinforced oil palm shell concrete. Mater. Des. 2013, 49, 1034-1041. [CrossRef]

29. Djobo, J.N.Y.; Elimbi, A.; Tchakouté, H.K.; Kumar, S. Volcanic ash-based geopolymer cements/concretes: The current state of the art and perspectives. Environ. Sci. Pollut. Res. 2017, 24, 4433-4446. [CrossRef]

30. Allahverdi, A.; Shaverdi, B.; Najafi, K.E. Influence of Sodium Oxide on Properties of Fresh and hardened paste of alkali activated blast furnace slag. Int. J. Civ. Eng. 2010, 8, 304-314. 
31. Sood, D.; Hossain, K.M.A. Optimizing Precursors and Reagents for the Development of Alka-li-Activated Binders in Ambient Curing Conditions. J. Compos. Sci. 2021, 5, 59. [CrossRef]

32. Sood, D.; Hossain, K.M.A.; Manzur, T.; Hasan, M.J. Developing Geopolymer Pastes Using Dry Mixing Technique. In Proceedings of the 7th International Conference on Engineering Mechanics and Materials (CSCE 2019), Laval, QC, Canada, 12-15 June 2019; pp. 12-15.

33. Sherir, M.A.; Hossain, K.M.; Lachemi, M. Self-healing and expansion characteristics of cementitious composites with high volume fly ash and MgO-type expansive agent. Constr. Build. Mater. 2016, 127, 80-92. [CrossRef]

34. Sherir, M.A.; Hossain, K.M.; Lachemi, M. Permeation and Transport Properties of Self-Healed Cementitious Composite Produced with MgO Expansive Agent. J. Mater. Civ. Eng. 2018, 30, 1-12. [CrossRef]

35. ASTM C109/C109M-16. Standard test Method for Compressive Strength of Hydraulic Cement Mortars (Using 2-in. or [50-mm] Cube Specimens); ASTM International: West Conshohocken, PA, USA, 2016.

36. Nematollahi, B.; Sanjayan, J.; Ahmed Shaikh, F.U. Tensile Strain Hardening Behavior of PVA Fiber-Reinforced Engineered Geopolymer Composite. J. Mater. Civ. Eng. 2015, 10, 04015001. [CrossRef]

37. Karihaloo, B.L.; Nallathambi, P. Effective Crack Model For The Determination Of Fracture Toughness Kfj Of Concrete. Eng. Fract. Mech. 1990, 415, 631-645.

38. ASTM C490/C490M-17. Standard Practice for Use of Apparatus for the Determination of Length Change of Hardened Cement Paste, Mortar, and Concrete; ASTM International: West Conshohocken, PA, USA, 2017.

39. ASTM C596-17. Standard Test Method for Drying Shrinkage of Mortar Containing Hydraulic Cement; ASTM International: West Conshohocken, PA, USA, 2017.

40. ASTM C157/C157M-17. Standard Test Method for Length Change of Hardened Hydraulic-Cement Mortar and Concrete; ASTM International: West Conshohocken, PA, USA, 2017.

41. ASTM C1585-13. Standard Test Method for Measurement of Rate of Absorption of Water by Hydraulic- Cement Concretes; ASTM International: West Conshohocken, PA, USA, 2013.

42. ASTM C666-15. Standard Test Method for Resistance of Concrete to Rapid Freezing and Thawing; ASTM International: West Conshohocken, PA, USA, 2015.

43. Kan, A.; Demirbog, R. A novel material for lightweight concrete production. Cem. Concr. Compos. 2009, 31, 489-495. [CrossRef]

44. Özbay, E.; Sahmaran, M.; Lachemi, M.; Yücel, H.E. Effect of Microcracking on Frost Durability of High-Volume Fly-Ash and Slag-Incorporated Engineered Cementitious Composites. ACI Mater. J 2013, 110, $259-267$.

45. Özbay, E.; Karahan, O.; Lachemi, M.; Hossain, K.M.; Atis, C.D. Dual effectiveness of freezing-thawing and sulfate attack on high-volume slag-incorporated ECC. Compos. Part B 2013, 45, 1384-1390. [CrossRef]

46. ACI Committee 318. Building Code Requirements for Structural Concrete and Commentary, ACI 318-19; American Concrete Institute: Farmington Hills, MI, USA, 2019.

47. Karihaloo, B.L.; Nallathambi, P. Effective crack model for the determination of fracture toughness (KIce) of concrete. Eng. Fract. Mech. 1990, 35, 637-645. [CrossRef]

48. Nematollahi, B.; Sanjayan, J.; Qiu, J.; Yang, E.-H. High ductile behavior of a polyethylene fiber-reinforced one-part geopolymer composite: A micromechanics-based investigation. Arch. Civ. Mech. Eng. 2017, 17, 555-563. [CrossRef]

49. Zhang, S.; Li, V.C.; Ye, G. Micromechanics-guided development of a slag/fly ash-based strain-hardening geopolymer composite. Cem. Concr. Compos. 2020, 109, 103510. [CrossRef]

50. Batista, R.P.; Trindade, A.C.C.; Borges, P.H.; Silva, F.D.A. Silica fume as precursor in the development of sustainable and high-performance MK-based alkali-activated materials reinforced with short PVA fibers. Front. Mater. 2019, 6, 1-15. [CrossRef]

51. Alrefaei, Y.; Dai, J.G. Tensile behavior and microstructure of hybrid fiber ambient cured one-part engineered geopolymer composites. Constr. Build. Mater. 2018, 184, 419-431. [CrossRef]

52. Punurai, W.; Kroehong, W.; Saptamongkol, A.; Chindaprasirt, P. Mechanical properties, microstructure and drying shrinkage of hybrid fly ash-basalt fiber geopolymer paste. Constr. Build. Mater. 2018, 186, 62-70. [CrossRef]

53. Chi, M.; Huang, R. Binding mechanism and properties of alkali-activated fly ash/slag mortars. Constr. Build. Mater. 2013, 40, 291-298. [CrossRef]

54. Shahrajabian, F.; Behfarnia, K. The effects of nano particles on freeze and thaw resistance of alka-li-activated slag concrete. Constr. Build. Mater. 2018, 176, 172-178. [CrossRef]

55. Pan, Z.; Tao, Z.; Cao, Y.F.; Wuhrer, R.; Murphy, T. Compressive strength and microstructure of alka-li-activated fly ash/slag binders at high temperature. Cem. Concr. Compos. 2018, 86, 9-18. [CrossRef] 